\title{
ESTUDIOS SOBRE PAISAJE Y POBLAMIENTO RURALES EN EL MEDIEVO ANDALUZ: BALANCE HISTORIOGRÁFICO
}

\author{
JAVIER LÓPEZ RIDER ${ }^{1}$ \\ Universidad de Córdoba
}

Recibido: 22 de septiembre de 2017

Aceptado: 15 de enero de 2018

\begin{abstract}
Resumen
A través de este trabajo se hace una revisión de las contribuciones que se han venido desarrollando sobre dos importantes elementos estrechamente relacionados: poblamiento y paisaje rurales. Ante la amplia producción historiográfica existente, se ha delimitado el análisis a la geografía andaluza y circunscrito al periodo bajomedieval. Se detallarán los principales enfoques de investigación y los resultados obtenidos, que permiten valorar de manera global, la atención que se le ha dedicado y el conocimiento adquirido sobre este marco temático. Asimismo, se plasmarán las líneas futuras que pueden renovar y mejorar dichos resultados y que se están desarrollando en la actualidad.
\end{abstract}

\section{Palabras clave}

Revisión historiográfica; Andalucía; Baja Edad Media; paisaje; poblamiento.

\begin{abstract}
Through this paper it is review of the contributions that have been developed on two important issues closely related: rural settlement and landscape. In view of the extensive existing historiographical production, the analysis has been geographically limited to Andalusia and chronologically circumscribed to the Late Medieval period. By explaining the main research approaches and the results of this study, it has been able to globally appreciate the interest shown in the topic and the acquired knowledge in this thematic field. It concludes by suggesting present and future lines of research, some of which are already being developed, that may contribute to improve these results.
\end{abstract}

\section{Keywords}

Historiographical review; Andalusia; Late Middle Ages; landscape; settlement.

\section{Résumé}

A travers cet article, on dressera un état des contributions récentes sur deux importants sujets étroitement reliés entre eux : peuplement et paysage ruraux. Face à la vaste production historiographique existante, on limitera l'analyse à la géographie de l'Andalousie à la fin de la période médiévale. On exposera les méthodes de recherche et les résultats obtenus. Ceux-ci permettent d'évaluer de manière globale

1 Correo electrónico: 152lorij@uco.es. ORCID: https://orcid.org/0000-0002-8412-921X. 
l'attention qu'on leur a portée ainsi que les connaissances acquises dans ce cadre thématique. En outre, on ébauchera les lignes futures susceptibles de renouveler et d'améliorer ces résultats, qui sont actuellement en cours d'élaboration.

\section{Mots-clés}

Bilan historiographique; Andalousie; Bas Moyen Age; paysage; règlement.

\section{Introducción}

Para la zona meridional de la Península Ibérica, las líneas maestras de investigación medieval parece que han tratado de responder, inconscientemente, a las preguntas que Ladero Quesada se hizo a finales de los años setenta ${ }^{2}$. Como bien apuntó en aquel momento, poco o nada se sabía sobre temas como las jurisdicciones de términos municipales tras la conquista y repoblación castellana, el progreso de los paisajes rurales, la organización de los espacios, la articulación territorial mediante diversas estructuras (fuentes, caminos, torres, viviendas, cortijos, etc...) o las transformaciones del poblamiento. Desde entonces se ha avanzado mucho en estos aspectos, existiendo una extensa nómina de historiadores que han investigado con ahínco esta temática.

El propio Ladero Quesada, por partida doble, ha realizado una valoración de la producción historiográfica ${ }^{3}$. No ha sido el único, también existen revisiones en los noventa de la mano de Cabrera Muñoz ${ }^{4}$, Collantes de Terán ${ }^{5}$ o González Jiménez, de quien la última aportación sobre los orígenes de Andalucía data de hace escaso tiempo ${ }^{6}$. Todos ellos arrancan de fines de los años setenta y ochenta para comenzar a encontrar los primeros resultados. Con el transcurrir del tiempo las publicaciones han ido aumentando, a la par que se han desarrollado distintos congresos, coloquios y jornadas para este marco territorial ${ }^{7}$. En las páginas de estas reuniones científicas así como en otras publicaciones, aparece numerosa información sobre una destacada miscelánea temática. Sin embargo,

\footnotetext{
LADERo QuesadA, "La investigación histórica”, pp. 217-250. Parte de la información plasmada en este artículo procede del tomo 1 de nuestra tesis doctoral: Santaella y el suroeste de la Campiña, Córdoba, 2017 (identificador: http://helvia.uco.es/xmlui/handle/10396/14903).

3 Además de la ya citada para finales de los setenta, tiene un trabajo más actual, LADERo QuesadA, "Andalucía en la Baja Edad Media", pp. 21-78.

4 Cabrera MuÑoz, "La investigación sobre Andalucía", pp. 121-155. Y también más reciente, Cabrera MuÑoz, "Tópicos y realidades", pp. 179-202.

5 Collantes de Terán SÁnchez, “Andalucía I. La investigación”, pp. 221-236.

6 GonzÁlez JimÉnez, "La investigación en Historia Medieval”, pp. 107-124 y GonzÁlez JimÉnez, “¿Qué es Andalucía?: Una revisión histórica", pp. 9-36.

7 Congresos: Andalucía. Medieval. Actas del I Congreso de Historia de Andalucía; Andalucía Medieval: Actas del II Congreso de Historia de Andalucía; Andalucia Medieval: Actas del III Congreso de Historia de Andalucía. En cuanto a coloquios y jornadas: Actas del I Coloquio de Historia Medieval Andaluza; Actas del II Coloquio de Historia Medieval Andaluza; Actas del III Coloquio de Historia Medieval Andaluza; Segura Graíño (coord.), Actas del IV Coloquio de Historia Medieval Andaluza; Cabrera Muñoz, Actas del V Coloquio Internacional de Historia Medieval de Andalucía; López de Coca Castañer y Galán Sánchez (coords.), Actas del VI Coloquio Internacional de Historia Medieval de Andalucía; Pérez-EMBID WambA (coord.), La Andalucía medieval: Actas de las I Jornadas de Historia Rural y Medio Ambiente; TORo CEBAllos y Rodríguez molina (coords.), VI Estudios de Frontera; Malpica Cuello, Peinado Santaella y Fábregas
} 
siempre hay referencias acerca del poblamiento y el paisaje rural, que poco a poco se han convertido en un objeto de estudio principal para muchos investigadores. A raíz de la década de los noventa se produjo un giro repentino y una mayor diversificación en los temas a investigar, ocasionando que esos dos elementos señalados, se relanzasen de manera abrumadora. Tal y como señalara Cabrera Muñoz, investigar sobre el poblamiento fue parte de "una moda" enfoques de los proyectos desarrollados, una mayor diversidad en las líneas de trabajo, y sobre todo, más calidad en los resultados adquiridos. Para el siglo XXI, el marco andaluz ha seguido gozando de muy buenos trabajos que han ido arrojando nuevos datos sobre la estrecha relación que hay entre el poblamiento y el territorio, originándose como fruto de esa interacción diferentes paisajes. En este sentido, es novedoso cómo el paisaje rural ha ido ganando más adeptos, convirtiéndose en un eje temático notable en la actualidad. Como plasmó Martín Gutiérrez en 2007, ya desde los años noventa, se afrontan multitud de aspectos que tienen en común precisamente al paisaje como protagonista ${ }^{9}$. No obstante, todavía quedan elementos en los que profundizar y analizar pormenorizadamente.

De este modo, el objetivo del presente trabajo es hacer una valoración de la producción existente sobre el poblamiento y el paisaje rurales hasta la actualidad. Ante la ingente cantidad bibliográfica que existe afortunadamente para toda España, se ha decidido circunscribir este artículo a una zona geográfica concreta, el marco andaluz, y a un periodo cronológico determinado, la Baja Edad Media. Ante la dificultad que entraña el llevar a cabo una visión totalitaria de todo lo realizado hasta la fecha, se hará mayor hincapié en las obras más destacadas y conocidas, teniendo en cuenta la última revisión historiográfica ya citada sobre paisaje rural efectuada por el profesor Martín Gutiérrez.

\section{Evolución historiográfica: de la reconquista al paisaje rural}

Aunque la investigación desarrollada en los últimos años para la Andalucía bajomedieval ha permitido adentrarse en cantidad de temas variados, la clara relación entre poblamiento y territorio ha ido originando que cada vez adquiriera más importancia el paisaje rural. Son abundantes los estudios realizados desde la segunda mitad del siglo XX hasta la actualidad, donde cualquier objeto de investigación ha manejado, desde perspectivas diferentes, el binomio paisaje/poblamiento.

\subsection{Reconquista y repoblación}

Un primer aspecto directamente relacionado con el paisaje, es el hecho de conquistar un territorio y destinarlo al asentamiento de una nueva sociedad rural determinada. Esto

\footnotetext{
García, Historia de Andalucía: VII Coloquio “QQué es Andalucía?”, y MARTín GutiérReZ, Actas de las I Jornadas Internacionales sobre paisajes rurales en época medieval.

8 CABRera MuÑoz, "La investigación sobre Andalucía", p. 659.

9 Martín Gutiérrez, "El paisaje rural como objeto de estudio", p. 125.
} 
conlleva a la implantación de un poblamiento diferente que aplicará una "organización social del espacio" distinta a la que existía con anterioridad. Con este concepto, cuyo precursor fue García de Cortázar, se produjeron nuevos aires de innovación de planteamientos y metodologías de trabajo ${ }^{10}$. Defiende la necesidad de conocer el desarrollo de la sociedad sobre el espacio geográfico puesto que:

"no basta con interesarse por la producción de recursos, el comercio de bienes, la dialéctica entre repoblación y despoblación, los modelos de poblamiento o los comportamientos biológicos de plantas y animales. Sin duda, los estudios sobre cada una de esas áreas de interés ofrecen postas y sugerencias para una historia del medio ambiente"11.

En este momento cobra vigor la idea de que cada sociedad ha ido modificando el territorio en el que desarrolla su vida diaria y lo ha adaptado a sus necesidades creando, a su vez, diferentes paisajes. Este historiador lo revela muy bien indicando que "cada sociedad tiene una forma de organización del espacio, lo que incluye unas modalidades específicas de relación con el espacio natural para transformarlo en paisaje" ${ }^{\prime 2}$. Idea que Malpica Cuello también comparte al señalar que "cada sociedad tiene una forma distinta de organizar el espacio, en consecuencia, su instalación en el medio físico es distinta"13. Y por ello, esa vinculación entre sociedad rural y entorno deben ser estudiadas "en el marco concreto de una sociedad y un medio físico que se humaniza, ambos perfectamente localizados en el espacio y el tiempo"14.

Todo ello origina unos paisajes distintos compuestos por varios niveles de información. Esto ha sido de gran interés en la historiografía hispana, con mayor raigambre en el marco andaluz, donde la reconquista y la repoblación no han dejado de permanecer en los objetivos de muchos proyectos de investigación. Por una parte, el fenómeno de la reconquista vuelve a ser muy estudiado, sobre todo desde un punto de vista historiográfico y conceptual. Muestra de ello son las publicaciones que vienen apareciendo desde el año 2002. El propio concepto reconquista es puesto a examen a causa de la ambigüedad que lo caracteriza, motivado por las diferentes interpretaciones que se le han atribuido. Esto ha generado una gran problemática a la hora de su utilización y suscitado numerosos debates. Una muestra de ello son las líneas escritas por Ladero Quesada en $1998^{15}$ o la

\footnotetext{
10 Con el vocablo "organización social del espacio" abrió el camino de esta temática de estudio en la obra que coordinó junto a otros autores denominada Organización social del espacio en la España Medieval., y posteriormente, Del Cantábrico al Duero. Asimismo, entre sus publicaciones más recientes, destacan "Sociedad rural y medio físico en la España Medieval", pp. 15-42; Sociedad y organización del espacio o "Sociedad rural y entorno físico", pp. 251-274.

11 García de Cortázar, "Sociedad rural y entorno físico", p. 254.

12 Ibid., p. 253.

13 Malpica Cuello, "Una propuesta de análisis", p. 16.

14 García de CortÁzar "Sociedad rural y entorno físico", p. 272.

15 "Actualmente, muchos consideran espurio el término reconquista para describir la realidad histórica de aquellos siglos, y prefieren hablar simplemente de conquista y sustitución de una sociedad y una cultura, la
} 
revisión que hizo Benito Ruano ${ }^{16}$. Recientemente Ríos Saloma ha llevado a cabo trabajos muy centrados en reseñar todo el panorama historiográfico al respecto ${ }^{17}$. Un extenso y minucioso artículo es el de García Fitz, que desmenuza los significados y usos que se le ha dado a la reconquista, desde una realidad de expansión territorial de los reinos cristianos, como datación para un periodo de tiempo determinado hasta como justificación para idear una guerra ${ }^{18}$. Desde Andalucía, existen varios historiadores que han trabajado sobre la reconquista, entre los que destaca González Jiménez, que ha efectuado distintos estados de la cuestión y valoración de las posturas existentes ${ }^{19}$. En los años ochenta, la contribución procedente de hispanistas también ha ido enriqueciendo el panorama historiográfico sobre el fin del periodo musulmán y la etapa reconquistadora ${ }^{20}$. Unido a lo anterior, la repoblación es otro concepto muy importante y que ha sido estudiado durante muchos años. De hecho, si se realiza una búsqueda de la bibliografía existente hasta el momento sobre la historia andaluza bajomedieval, una característica de un gran porcentaje de las publicaciones es su dedicación a la instalación de los cristianos en los nuevos territorios adquiridos. Aparecen estudios sobre los tipos de asentamientos, la evolución del poblamiento y su relación con el medio, las relaciones económicas que desempeñan o pesquisas sobre la demografía y análisis de los paisajes medievales. Por ejemplo, Ladero Quesada viene proporcionando datos desde hace más de treinta años ${ }^{21}$. En este sentido y como es sobradamente conocido, los denominados Libros de Repartimiento han permitido profundizar, en la medida de lo posible, sobre la ocupación del territorio y posterior establecimiento poblacional cristiano de algunas regiones. Al respecto, no cabe duda que Julio González ha sido uno de los pioneros en analizar estos aspectos en Andalucía, como se plasman en sus trabajos ${ }^{22}$. Muchas de sus obras, como la dedicada a Sevilla son, hoy por hoy, recopilaciones de documentos medievales muy útiles para continuar investigando. Con el surgimiento del regionalismo, la bibliografía sobre esta materia comenzó aumentar

andalusí, por otra, la cristiano-occidental; pero aunque esto fue así, también lo es que el concepto de reconquista nació en los siglos medievales y pertenece a su realidad en cuanto que sirvió para justificar ideológicamente muchos aspectos de aquel proceso” en LADERo QuesADA, “¿Es todavía España un enigma histórico?”, p. 334.

16 Benito Ruano, "La Reconquista", pp. 91-98.

17 Ríos Saloma, "La Reconquista: génesis de un mito historiográfico", pp. 191-216; "La "Reconquista": una aspiración peninsular?", pp. 1-15 y La Reconquista, una construcción historiográfica.

18 García Fitz, La Reconquista y "La Reconquista: un estado de la cuestión”, pp. 142-215.

19 GonZÁlez Jiménez, “¿Re-conquista?”, pp. 155-178; “Sobre la ideología de la Reconquista”, pp. 151-170; "La Reconquista: realidad y leyenda", pp. 131-146.

20 Lomax, "La conquista de Andalucía", pp. 37-50; Mackay, La España de la Edad Media; Glick, Islamic and Christian Spain; O'Callaghan, Reconquest and crusade; Cressier, "Las fortalezas musulmanas de la Alpujarra", pp. 179-200; Cressier, "La château et la division territoriale", pp. 115-144; Cressier, "Dalías y su territorio", pp. 89-120; Cressier, "El patrimonio almohade de Almería", pp. 91-102; Cressier, "Vigilar, proteger, habitar. A propósito de las torres", pp. 209-214; GuICHARD, Al-Ándalus: estructura antropológica; Guichard, De la expansión árabe a la Reconquista, y más reciente, Guichard, "Córdoba, de la conquista musulmana a la conquista cristiana", pp. 5-24.

21 Ladero Quesada, "La población de Andalucía en el siglo XV", pp. 479-496; "Las ciudades de Andalucía occidental", pp. 159-295 o "La población de reinos y ciudades en la baja edad media", pp. 37-78.

22 GonzÁlez, Las conquistas de Fernando III en Andalucia; Reinado y diplomas de Fernando III o Repartimiento de Sevilla. 
notablemente, ya que otros investigadores comenzaron a realizar trabajos dedicados al poblamiento y población andaluza de los siglos bajomedievales sobre ámbitos geográficos más delimitados. Segura Graíño, en la década de los ochenta, llevó a cabo una exitosa labor desmenuzando toda la información posible sobre repartimientos andaluces y proporcionando datos sobre Almería ${ }^{23}$. Para esta región, Franco Silva hizo un estudio sobre las villas de los Vélez, aportando algunos datos sobre su demografía y Grima ha examinado la tierra de Mojácar ${ }^{24}$. Hace apenas unos años, se publicó un artículo sobre poblamiento en la zona céntrica de la provincia almeriense ${ }^{25}$. Desde Sevilla la trabajosa y formidable tarea de González Jiménez, ha contribuido enormemente no solo al ámbito hispalense, sino también a la historia medieval andaluza en general. Sus aportaciones comenzaron en los años setenta y aún mantienen plena actualidad ${ }^{26}$. En Sevilla, también han realizado algunos estudios sobre esta temática, Borrero Fernández, Collantes de Terán o García Fernández, centrándose en el poblamiento y población rurales ${ }^{27}$. Del mismo modo, es importante el artículo de Sanz Fuentes sobre el repartimiento de Écija ${ }^{28}$. Para Córdoba, Cabrera Muñoz además de centrarse en Andalucía, es quién más ha publicado hasta el momento sobre

23 Segura Graíño, El libro del Repartimiento de Almería; La formación del pueblo andaluz; "Los repartimientos medievales andaluces", pp. 625-640; "Poblaciones recientes sobre la historia de Andalucía en la Edad Media”, pp. 421-427; "Presencia portuguesa en la conquista y repoblación de Almería”, pp. 841-849. Un balance de los trabajos realizados sobre poblamiento almeriense hasta el año 2006 en GARCía PARDO, "Los estudios de población y poblamiento en Almería", pp. 279-296.

24 Franco Silva, "Datos demográficos y organización municipal de las villas almerienses", pp. 85-112; Grima Cervantes, La Tierra de Mojácar.

25 Martín Civantos y Arod, "Poblamiento medieval en la cuenca alta del río Nacimiento (Almería)", pp. 35-61.

26 GonzÁlez Jiménez, La repoblación de la zona de Sevilla en el siglo XIV; con GonzÁlez Gómez, El Libro de repartimiento de Jerez de la Frontera; "Repartimiento de Carmona”, pp. 59-84; con BARTOLOMÉ SomozA, Carta-puebla otorgada a el Gran Puerto de Santa María; "La obra repobladora de Alfonso X en las tierras de Cádiz”, pp. 7-19; “Andalucía Bética”, pp. 163-194; “Conquista y repoblación de Alcalá de Guadaira”, pp. 135-158; "Reconquista y repoblación del Occidente peninsular", pp. 455-489; "Población y repartimiento de Écija”, pp. 691-712; "Repartimientos andaluces del siglo XIII”, pp. 103-122; "Repoblación y repartimiento de Écija", pp. 337-365; En torno a los orígenes de Andalucia; "Poblamiento y frontera en Andalucía", pp. 207-224; "Los ritmos de la repoblación", pp. 215-227; Diplomatario andaluz de Alfonso X; "Del Duero al Guadalquivir", pp. 209-224; "Poblamiento en la Baja Andalucía", pp. 63-86; "La obra repobladora de Fernando III en Jaén y Córdoba", pp. 287-312; "El repartimiento de Carmona”, pp. 199-224; GonZÁLEZ JiMÉNEZ (coord.), Sevilla 1248. Congreso Internacional conmemorativo del 750 aniversario de la conquista de la ciudad de Sevilla por Fernando III; "Alfonso X, repoblador", pp. 17-32; La repoblación del reino de Sevilla en el siglo XIII; GonzÁlez Jiménez et alii, "Las villas nuevas de Andalucía en la Edad Media", pp. 349-370; "Constantina en el siglo XIII”, pp. 35-50; "La repoblación de Andalucía”, pp. 295-302 y La repoblación de la zona de Sevilla durante el siglo XIV.

27 Borrero Fernández, "El poblamiento rural sevillano", pp. 319-335; "El concejo de Fregenal”, pp. 113168; "La población de Lora del Río", pp. 39-48 y "Situación demográfica de la Sierra Norte de Sevilla", pp. 43-72. Collantes de Terán, Sevilla en la Baja Edad Media; "Nuevas poblaciones del siglo XV”, pp. 283-336; "Los padrones militares de la Andalucía bajomedieval”, pp. 287-294; "Evolución demográfica", pp. 21-33; "Los efectivos humanos", pp. 75-98. GARcía FernándEz, "La carta puebla del castillo de Cote", pp. 57-68; "Nuevos datos sobre la repoblación del sector sur", pp. 145-160; La campiña sevillana y la frontera de Granada; "Gibraltar, conquista y repoblación”, pp. 155-169 y "Alfonso XI y la villa de Teba”, pp. 203-213.

28 SAnZ Fuentes, "Repartimiento de Écija”, pp. 534-551. 
repoblación y reconquista del reino de Córdoba $^{29}$. El medievalista del Pino García ha sido otro de los investigadores que ha aportado algunos datos inéditos para la jurisdicción del reino de Córdoba. Se ha circunscrito a lugares de carácter rural como Monturque, Luque, Puente Genil, el despoblado de Cuzna o en zonas más amplias como la Campiña, de la cual hizo una reflexión sobre lo que se conocía del poblamiento y el territorio hasta ese instante ${ }^{30}$. También debe ser citado el hispanista John Edwards, especializado en esta zona de la Corona castellana. Ha investigado diversos aspectos (política, frontera, violencia, nobleza) destacando sobre todo su monografía, donde ya recogió información sobre poblamiento, territorio y paisaje $\mathrm{e}^{31}$. Al mismo tiempo, Córdoba de la Llave, experto en temas industriales y de conflictividad, posee trabajos muy completos sobre aspectos relacionados con el hábitat medieval y su vinculación con sus entornos rurales. Por ejemplo, aporta datos de núcleos de población rural como Valenzuela y Almodóvar del Río o sobre despoblados como Teba o Castro el Viejo ${ }^{32}$. Por mi parte, estoy contribuyendo con el estudio del poblamiento y el paisaje de la Campiña cordobesa, revisando la terminología de las diferentes unidades de población rural, incluyendo una profunda reflexión sobre despoblados y su reflejo en todo el paisaje ${ }^{33}$. Los trabajos de Carpio Dueñas, han hecho hincapié en el poblamiento y la tierra de la jurisdicción cordobesa. En su monografía, que es el resultado de su tesis doctoral, se encuentra un capítulo sobre la articulación del término rural de Córdoba. También habló del tipo de poblamiento y de la formación del territorio medieval, aunque aparece más información sobre la región septentrional cordobesa $^{34}$. Otros investigadores a tener en cuenta, son Sanz Sancho, Escobar Camacho y Nieto Cumplido. El primero de ellos, tuvo mucho interés en el ámbito eclesiástico cordobés. Llegó a publicar varios trabajos sobre la geografía eclesiástica del obispado de la ciudad y su hábitat rural, proporcionando importantes datos como base para elaborar un estudio en profundidad sobre el poblamiento ${ }^{35}$. En cuanto al segundo, posee estudios tanto del reino de Córdoba como de algunas de sus villas, proporcionando información

\footnotetext{
29 Entre otras publicaciones: CABRERA MUÑOz, "Reconquista, repoblación y estructuras agrarias", pp. 1-31; "Reconquista, organización territorial y restauración eclesiástica”, pp. 313-334; "Notas sobre la conquista y la organización territorial del reino de Córdoba", pp. 83-100; y más recientes, "Algunos datos e ideas sobre el Repartimiento de Córdoba", pp. 141-148 o junto a otros autores, Orígenes históricos de Villafranca de Córdoba. También ha escrito sobre Andalucía, por ejemplo, "Reflexiones sobre los repartimientos y la repoblación de Andalucía", pp. 303-318 o "Repoblación y señoríos en Andalucía", pp. 1109-1124.

30 Del Pino García, "Monturque en la Edad Media”, pp. 175-344; junto a CARPio Dueñas, "Los Pedroches y el despoblado medieval de Cuzna", pp. 177-200; de nuevo en solitario, "De Castillo Anzur a Puente don Gonzalo", pp. 243-260; "Poblamiento y organización social”, pp. 41-80 y "Luque en la Baja Edad Media”, pp. 203-232.

31 Edwards, Christian Cordoba.

32 Córdoba de la Llave, “Almodóvar del Río”, pp. 45-69; "El hábitat de Teba (Santa Cruz, Córdoba)", pp. 102-110; "El castillo de Castro el Viejo", pp. 131-139 y "Valenzuela y su territorio", pp. 173-201.

33 LÓPEZ RIDER, "Organización y configuración territorial", (en prensa); "The vegetal landscape of the southwest of Cordoba”, pp. 364-384, Santaella y el suroeste de la Campiña (identificador: http://helvia. uco.es/xmlui/handle/10396/14903) y "Paisajes hídricos y poblamiento en la Campiña cordobesa a fines de la Edad Media", pp. 111-145.

34 Carpio Dueñas, La tierra de Córdoba, pp. 23-105.

35 SAnz SAncho, La Iglesia y el obispado de Córdoba; Geografía del Obispado de Córdoba y junto a DEL PINO GARCíA, "Parroquias y núcleos rurales", pp. 5-17.
} 
bastante útil aunque extraída, en su mayoría, de los volúmenes del Corpus Mediaevale Cordubense $^{36}$. Nieto Cumplido, además de realizar este corpus documental, posee varios trabajos que son fundamentales como apoyo al análisis del hábitat bajomedieval y su incidencia en el paisaje rural $^{37}$.

En Jaén Rodríguez Molina abordó aspectos demográficos y territoriales ${ }^{38}$. Sin embargo, será Alcázar Hernández la que profundice en esta línea de investigación, examinando la organización del territorio así como las unidades de población existentes en el reino jiennense y su evolución ${ }^{39}$. Castillo Armenteros y Salvatierra Cuenca ${ }^{40}$, están más especializados en arqueología del territorio y centrados en el periodo andalusí. Partiendo de Bejarano Robles, que sin duda ha sido el pionero en el estudio de los repartimientos de la zona malagueña ${ }^{41}$, serán las publicaciones de López de $\mathrm{Coca}^{42}$ las que proporcionen bastantes datos sobre el repartimiento y poblamiento de aquella zona. En menor medida y más orientados hacia determinados lugares de la comarca malagueña, aparecen Ruiz Povedano $^{43}$, Alijo Hidalgo, muy adherido a Antequera y su tierra ${ }^{44}$, Galán Sánchez, que ha profundizado en la zona costera (Marbella y Estepona) ${ }^{45}$ o Martín acerca de los repartimientos de Vélez-Málaga ${ }^{46}$. Finalmente, es destacable la tesis que elaboró Acién Almansa sobre Ronda en el reinado de los Reyes Católicos ${ }^{47}$ y el estudio de los despoblados de esta región a cargo del conocido Cabrillana ${ }^{48}$.

Sobre Cádiz, existen diversos trabajos que han ido abarcando el poblamiento y el desarrollo territorial de ese ámbito geográfico, unos enmarcados en un panorama más general y otros circunscritos a ciertas partes de la provincia ${ }^{49}$. Actualmente, Martín

\footnotetext{
36 Escobar Camacho, "El reino de Córdoba en la época de Alfonso X", pp. 105-119; "La campiña de Córdoba", pp. 57-75; "Benamejí durante los siglos bajomedievales", pp. 41-54; "La Rambla durante la Edad Media", pp. 35-60; "Las cuevas de Carchena", pp. 11-26; "De la Córdoba islámica a la cristiana", pp. 69-94; "La Córdoba bajomedieval", pp. 83-132 e Historia de Hornachuelos.

37 Nieto Cumplido, Corpus Mediaevale Cordubense; Villa del Río; "Castro del Río"; "Santaella en la Edad Media", pp. 41-83; "El «Libro de diezmos de donadíos»", pp. 125-162 y La historia de la Iglesia en Córdoba.

38 Rodríguez Molina, El Reino de Jaén, pp. 283-285.

39 Alcázar Hernández y Salvatierra Cuenca, "La organización del poblamiento castellano en la Sierra de Segura", pp. 373-396; AlCÁZAR Hernández, "Formación y articulación de un concejo fronterizo", pp. 255-286; "La dinámica de un territorio", pp. 105-161 y El Concejo de Jaén en la Baja Edad Media.

40 Útil para el periodo bajomedieval es SALVATIERRa Cuenca, "Jaén en los siglos XIII y XIV”, pp. 149-168.

41 Bejarano Robles, Los repartimientos de Málaga. Tomos I, II y III; Los repartimientos de Málaga IV; Los repartimientos de Málaga $V$ y Los repartimientos de Álora y de Cártama.

42 López DE Coca, "Bezmiliana, un despoblado", pp. 33-62; "Poblamiento y frontera en el obispado de Málaga", pp. 367-408; La tierra de Málaga a fines del siglo XV; "El repartimiento de Vélez Málaga", pp. 357-439; "La repoblación de Torrox", pp. 9-60 y "Fuengirola, un caso de repoblación fallida", pp. 55-60.

43 Ruiz Povedano, "Poblamiento y frontera", pp. 1-14 y "Transformación del paisaje urbano y territorial del Álora", pp. 3-19.

44 Alijo Hidalgo, "Castillos y lugares del Alfoz de Antequera", pp. 177-186 y Antequera y su tierra.

45 Galán Sánchez y Peinado Santaella, La repoblación de la costa malagueña.

46 Martín Palma, Los repartimientos de Vélez-Málaga: primer repartimiento.

47 Acién Almansa, Ronda y su Serranía.

48 Cabrillana, El problema de la tierra en Málaga.

49 SANCho de Sopranis, "La repoblación y el repartimiento", pp. 483-539; más centrado en el periodo musulmán, Abellán Pérez, "Los orígenes de Vejer de la Frontera”, pp. 7-18; "Aproximación al espacio rural
} 
Gutiérrez, ya citado en varias ocasiones, es el especialista más activo potenciando la investigación sobre organización del espacio, poblamiento, toponimia y paisaje rural ${ }^{50}$. Respecto a Huelva, González Jiménez escribió sobre su sierra ${ }^{51}$, pero también destacan las figuras de Pérez-Embid ${ }^{52}$ con algunas publicaciones sobre la temática tratada, García Sanjuán ${ }^{53}$, que a pesar de estar más dedicado a la historia de al-Ándalus ha trabajado también sobre la Baja Edad Media, Carriazo con numerosas obras sobre fortificaciones $^{54}$, y finalmente, un estudio sobre Niebla englobando el poblamiento y su territorio ${ }^{55}$. En último lugar, hay que citar la producción bibliográfica sobre las formas de poblamiento y ordenación geográfica del reino de Granada, pues en los últimos años es una de las regiones que más actividad está manifestando ${ }^{56}$. El grupo de investigadores asentados en la universidad granadina ha llevado a cabo numerosos estudios que abarcan desde los repartimientos, pasando por la economía y población, la importancia del medio físico, hasta los castillos y fortificaciones. También se ha apostado mucho por la arqueología del paisaje o del territorio, muy presente en las publicaciones. No cabe duda que Malpica Cuello es uno de los investigadores andaluces más dinámicos, ocupando un gran porcentaje del total de trabajos sobre época nazarí, con estudios muy completos al tener en consideración tanto la toponimia, las fuentes documentales como la arqueología ${ }^{57}$.

jerezano", pp. 13-20; "El despoblado de Beca", pp. 361-368; GonZÁlez JimÉnEZ (coord.), Repartimiento de El Puerto de Santa María; Los repartimientos de Vejer de la Frontera (1288-1318); Franco SiLva, "La organización social del territorio gaditano", pp. 313-326; "Notas sobre la villa de Alarcón”, pp. 187-206; más reciente, "Población y reparto de la propiedad en Chipiona", pp. 1319-1338; Anasagasti VaLderRama y Rodríguez LiáÑez, El Libro de repartimiento de Medina Sidonia y Ladero Quesada y GonZález Jiménez, "La población en la frontera de Gibraltar", pp. 199-316.

50 Martín Gutiérrez, "Aproximación al repartimiento rural en Jerez de la Frontera", pp. 355-368; La identidad rural de Jerez de la Frontera; "Análisis de la toponimia y aplicación al estudio del poblamiento", pp. 257-300; "Territorio. Paisaje. Poblamiento", pp. 33-56 y La organización del paisaje rural durante la Baja Edad Media.

51 Gonzélez Jiménez, "Los inicios de la repoblación de la Sierra de Huelva", pp. 365-374.

52 Pérez-Embid Wamba, "Un despoblado bajomedieval en el Aljarafe", pp. 145-149 y Aracena y su sierra.

53 GarCía SANJú́n, "La conquista de Niebla", pp. 89-112; "Poblamiento y organización del territorio onubense", pp. 89-106; Evolución histórica y poblamiento del territorio onubense y Hasta que Dios herede la tierra.

54 CARriazo Rubio, "La conquista cristiana. La cuestión del Algarbe", pp. 241-256; "Fronteras y fortificaciones en Andalucía Occidental", pp. 59-97; "Las fortificaciones del bajo Guadiana", pp. 81-94 у Huelva, tierra de castillos.

55 Anasagasti Valderrama y Rodríguez Liáñez, Niebla y su tierra en la Baja Edad Media.

56 Para una aproximación hasta los años noventa ver RodríGuez Molina, "Andalucía II. El reino de Granada", pp. 237-270.

57 De hecho, es responsable del Grupo de Investigación Toponimia, Historia y Arqueología del reino de Granada (http://www.ugr.es/ tharg/imagenesframe/indexgrame.htm). Entre los cientos de trabajos de este autor, se citan: Malpica Cuello, El concejo de Loja (1486-1508); "La villa de Motril y la repoblación de la costa de Granada", pp. 169-206; "Modificaciones en la estructura de poblamiento de la costa granadina", pp. 201-220; "La formación de un territorio fronterizo medieval", pp. 241-256; "Estructura del poblamiento de la costa de Granada", pp. 157-186; "Arqueología de los paisajes medievales granadinos", pp. 25-62; Poblamiento y castillos en Granada; "El paisaje vivido y visto", pp. 37-58; "El poblamiento y la organización del espacio", pp. 249-289; Los castillos en al-Ándalus y la organización del territorio; "El territorio de Loja a finales de la Edad Media", pp. 233-254 y "Un asentamiento fortificado en la frontera nazarí-castellana", pp. 197-225. 
Un tiempo atrás, Peinado Santaella, también ha ayudado al conocimiento del territorio y poblamiento granadino con una larga trayectoria de artículos, contribuciones a obras colectivas y monografías ${ }^{58}$. Siguiendo las directrices de los dos historiadores anteriores, existe un nutrido conjunto de medievalistas que están originando numerosos resultados no solamente para la ciudad de Granada, sino también para otras zonas. En este sentido, Trillo posee abundantes referencias acerca de la organización del espacio rural de La Alpujarra ${ }^{59}$. Por su parte, Quesada ha examinado el paisaje de Granada y de Jaén, arrancando desde el siglo XIII hasta fines de la Baja Edad Media ${ }^{60}$. Los mencionados Ladero Quesada y López de Coca, se han interesado por esta comarca de Andalucía, mejorando el conocimiento sobre el reino de Granada ${ }^{61}$. Muchos otros, sencillamente han profundizado en regiones determinadas, como Vélez Rubio ${ }^{62}$, Cenes de la Vega ${ }^{63}$, Almuñécar ${ }^{64}$, Baza $^{65}$, Loja ${ }^{66}$ o Guadix ${ }^{67}$.

\subsection{Articulación, control y aprovechamiento del paisaje bajomedieval}

La implantación de una nueva sociedad genera una transformación paulatina del territorio en el que se establece. Esa consolidación ha provocado que los núcleos de población rurales preparen y adapten ese territorio a sus necesidades, procurando que se origine

\footnotetext{
58 Peinado Santaella, "La repoblación de la Tierra de Granada", pp. 363-381; La repoblación de la tierra de Granada. Los Montes orientales (1485-1525); "La sociedad repobladora", pp. 477-524; "La repoblación del Reino de Granada. Estado de la cuestión", pp. 273-334; "Repoblación, organización y distribución del espacio en los Montes de Granada", pp. 559-575; "El Reino de Granada después de la conquista", pp. 15751630; Peinado Santaella y Osorio Pérez, "Del repartimiento al despojo", pp. 683-726; Peinado Santaella y OsORIo PÉrez, "El Libro de repartimiento de Montejícar (1527)”, pp. 71-112; "Una aportación documental sobre el poblamiento", pp. 19-92.

59 Trillo SAN José, "La alquería y su territorio en al-Ándalus", pp. 243-262; "La organización del espacio de la alquería", pp. 227-240; "El poblamiento de la Alpujarra", pp. 187-208; "Poblamiento medieval en la Alta Alpujarra", pp. 725-730; La Alpujarra antes y después de la conquista castellana; La Alpujarra al final de la Edad Media y "Comunidades rurales en el Reino Nazarí", pp. 103-118.

60 Quesada Quesada, "El poblamiento medieval en las sierras subbéticas", pp. 159-182; Quesada Quesada y JimÉNEZ SÁNCHEZ, "En los confines de la conquista castellana", pp. 51-80; "Formas de poblamiento en un área rural de al-Ándalus: el valle del río Jumilla", pp. 5-24; "Poblamiento y fortificación del territorio en los siglos XII-XIII", pp. 141-163 y Quesada Quesada y Motos Guirao, "Las modificaciones en el hábitat en el sur de la provincia de Jaén", pp. 377-382.

${ }^{61}$ López de Coca Castañer, "Privilegios fiscales y repoblación en el reino de Granada", pp. 205-223; "Los últimos repartimientos medievales: el Reino de Granada", pp. 309-342; LADERo QuesADA, Granada después de la conquista y LADERO Quesada, "Datos demográficos sobre los musulmanes de Granada", pp. 481-490.

62 Motos Guirao, "El Castellón de Vélez Rubio", pp. 5-14.

63 Calero Palacios, El apeo y repartimiento de Cenes de la Vega.

64 Calero Palacios, El libro de repartimiento de Almuñécar.

65 Pareja Serrano, El repartimiento de Baza y la repoblación y Torres Delgado, "La ciudad de Baza", pp. 747-794.

66 Además del ya citado trabajo de Malpica, ver Barrios Aguilera, "La población de Loja a raíz de su incorporación al Reino de Castilla", pp. 69-122; Libro de los repartimientos de Loja I; Los Repartimientos de Loja (1486-1510) y más reciente, JiMÉnez PuERTAS, El poblamiento del territorio de Loja en la Edad Media.

67 Asenjo Sedano, Guadix, la ciudad musulmana del siglo XV.
} 
una organización articuladora de todo ese espacio geográfico. En este sentido, son fundamentales los diferentes elementos que permiten esa ordenación como edificios de carácter residencial (viviendas), eclesiásticos (iglesias y ermitas), económicos (cortijos, caleras, herrerías, molinos, norias, ollerías, etc...) o militares (castillos y torres). Todos ellos poseen una determinada jurisdicción que provoca que el territorio se divida en diferentes escalas de utilización y beneficie el adecuado desarrollo de la población permanente en él. Así, por ejemplo, son primordiales las vías de comunicación, donde la red de caminos existente permite conectar con los diferentes núcleos de población, no solo entre ellos, sino también con el resto de unidades económicas, militares y eclesiásticas que se sitúan en sus alrededores. A su vez, la presencia de una infraestructura hidráulica repartida por el territorio deja entrever la gestión y consumo de los recursos hídricos existentes en el ámbito rural por parte de ese poblamiento, que al mismo tiempo, articula el territorio. Por supuesto, las instalaciones de carácter agropecuario e industrial ordenan el factor socioeconómico de cualquier área geográfica, administrando la zona de manera que se obtenga la mayor y mejor producción posible. Obviamente, todos los elementos anteriores deben estar protegidos a través de la cercanía de diversos castillos y torres de vigilancia, configurando en otro escalafón, ahora militar, el espacio territorial circundante. El gran interés que suscita el proteger todo el conglomerado de ordenaciones territoriales (residenciales, eclesiásticas, económicas, militares...) ha ido produciendo mayores conflictos a la hora de delimitar administrativamente las jurisdicciones de cada centro poblacional. Al llegar el siglo XV aumentan los índices demográficos e incrementan los asentamientos, en contrapartida, el espacio rural es más reducido y aprovechado, causando la necesidad de la presencia de jueces de términos para solucionar los problemas que se acontecían.

Cada una de las diversas capas de información anteriores, ha provocado que se obtengan numerosos y variados paisajes. Pero si se aúnan los contenidos de todas ellas, se entremezclan cada uno de esos paisajes, se obtiene el panorama de un paisaje general de un marcado carácter rural. Desde diferentes enfoques correlativos a cada uno de esos niveles de contenidos, se han venido haciendo muchos estudios que se ciñen a un análisis pormenorizado de cada paisaje. Una línea de investigación que desde los años ochenta ya comenzó a ser de gran interés, como así lo demuestran los trabajos de Romero-Camacho o Borrero Fernández sobre el paisaje rural hispalense ${ }^{68}$. También el profesor Martín Gutiérrez en su revisión realizada en 2007, recoge abundantes publicaciones que abarcan el análisis paisajístico desde miradas distintas, manifestándose la atención prestada a este marco temático ${ }^{69}$. Sin duda, esto ha generado el surgimiento de multitud de significados para un solo concepto, el cual se enriquece y se convierte en un término polisémico a tener muy en cuenta. De hecho, el propio García de Cortázar lo define como:

\footnotetext{
68 Montes Romero-CAmacho, Propiedad y explotación de la tierra en la Sevilla de la Baja Edad Media, y El paisaje rural sevillano en la Baja Edad Media; BorRERo FERNÁNDEZ, El mundo rural sevillano en el siglo XV y más reciente, Mundo rural y vida campesina o La organización del trabajo.

69 Martín GutiérRez, "El paisaje rural como objeto de estudio", pp. 121-150.
} 
"La traducción visible de la organización social del espacio generada por un grupo humano en función de sus necesidades y de las aspiraciones de beneficio y dominio por parte de la minoría que dirige aquel. Esto es condicionado por cuatro factores: los rasgos ecológicos del espacio, los efectivos de población, la estructura social y las dimensiones del mercado que dependen del grado de integración de una economía (local, comarcal, regional) en ámbitos económicos más amplios"70.

Desde aquella revisión hasta hoy día, en el marco andaluz se han venido realizando trabajos muy interesantes. Algunos de ellos abarcan el paisaje en general, mientras que otros, se ciñen al estudio de alguno de los niveles informativos que conforman ese propio paisaje. Partiendo de los trabajos citados previamente, donde tratan en ocasiones parte de las temáticas indicadas, hay otros que se centraron, con anterioridad al 2007, en cualquiera de los elementos que conforman el paisaje bajomedieval. Por ejemplo, una reflexión acerca de la influencia de las ciudades sobre el territorio la hizo Collantes de Terán para el marco andaluz $^{71}$. El sur del reino de Córdoba cuenta con diversas publicaciones destacables sobre el ámbito militar desde 1996 hasta la actualidad ${ }^{72}$. Aunque la mayoría están dedicados al periodo andalusí, se plasman ciertas referencias sobre el mantenimiento del uso de torres en la etapa cristiana. Así lo he podido detectar recientemente en mi tesis, donde incluso ha sido posible localizar algunas otras inéditas durante el dominio cristiano ${ }^{73}$. Por su parte, León Muñoz también ha realizado estudios sobre las fortificaciones del reino cordobés, aunque caracterizados por un perfil más arqueológico ${ }^{74}$. Del mismo modo, en Jaén los trabajos recientes de Salvatierra, y más aún de Alcázar Hernández, muestran los resultados del estudio del paisaje rural en los siglos bajomedievales desde la perspectiva militar ${ }^{75}$. En Granada existen trabajos recientes del profesor Malpica Cuello donde refleja la importancia de la conexión entre núcleos rurales de población, fortificaciones y paisaje ${ }^{76}$. Para

\footnotetext{
70 García de CoRTÁzar "Sociedad rural y entorno físico", p. 254.

71 Collantes de Terán SÁnchez, "Ciudad y territorio rural”, pp. 19-54.

72 Sánchez Villaespesa, "Las torres de la Campiña de Córdoba en el siglo XIII”, pp. 157-170; MartíneZ Castro y Tristell Muñoz, "Localizados los restos de la Torre de Albaén”, pp. 256-258; Martínez Castro, "Breves notas sobre la funcionalidad de las torres islámicas", pp. 79-83; "Una hipótesis sobre la ubicación de la torre islámica de Diezma Ayusa (campiña de Córdoba)", pp. 65-71; "El asentamiento medieval de Almazán”, pp. 11-19; "Fortificaciones y poblamientos islámicos del entorno de La Rambla”, pp. 33-82; "La Torre de Don Lucas (La Victoria, Córdoba)", pp. 137-171.

73 López Rider, Santaella y el suroeste de la Campiña, p. 646 y ss.

74 León MuÑoz, "Evolución arquitectónica de la fortaleza de Aguilar de la frontera (Córdoba)", pp. 209-232; El castillo de Aguilar de la Frontera; "Los castillos del reino de Córdoba", pp. 291-336; Las fortalezas de Belalcázar; "Las torres del homenaje como referentes del paisaje político bajomedieval", pp. 81-90; "Investigación castellológica e intervención arquitectónica", pp. 51-90; "Documentos emergentes, monumentos elocuentes", pp. 76-81; "Las fortificaciones castellanas en el siglo XV en el reino de Córdoba”, pp. 59-112 y "Las fortificaciones de la Córdoba Almohade", pp. 337-354.

75 Salvatierra Cuenca, "Jaén, tierra bien encastillada", pp. 94-97; AlCÁZAr Hernández, "La ciudad fronteriza y su territorio", pp. 181-204; Aldeas y cortijos medievales de Jaén; "Reflexiones y balance historiográfico", pp. 77-88 y "Las fortificaciones del concejo fronterizo de Jaén”, pp. 199-208.

76 Malpica Cuello, “Castillos, alquerías y ciudades en al-Ándalus", pp. 99-120 o "Fortificación en el mundo nazarí, pp. 30-37.
} 
Sevilla, Valor Piechotta en 2004 ya habló de las fortificaciones sevillanas bajomedievales y en 2011 coordinó un estudio sobre Constantina, donde se pone de relieve el ámbito militar y poblacional, entre otros aspectos, en el marco de dicha villa ${ }^{77}$. En el resto de provincias andaluzas, la producción ha sido menor, sin olvidar las diversas publicaciones de Carriazo Rubio para las fortificaciones onubenses ${ }^{78}$. Todos estos trabajos constituyen, como llamó Glick a su obra, unos "Paisajes de conquista" manifestando la vinculación entre estructuras militares, poblamiento y paisaje $\mathrm{e}^{79}$.

Desde el 2007 hasta la actualidad, existen también estudios centrados en el aspecto económico ejercido por el poblamiento y que genera la modificación del paisaje. Para el reino cordobés Carpio Dueñas ha llevado a cabo un par de trabajos muy interesantes, siendo de vital importancia el realizado en 2014 sobre la evolución del territorio de Madinat al-Zahra, donde analiza el ámbito de Córdoba la Vieja partiendo desde el año $1236^{80}$. Asimismo tanto Córdoba de la Llave como yo, hemos contribuido con diversos datos sobre la explotación rural del paisaje cordobés, demostrándose sobre todo, la gran importancia de la gestión y explotación de los recursos hídricos ${ }^{81}$. De este modo, se han recogido varios ingenios industriales e hidráulicos bajomedievales en numerosos cursos fluviales y esparcidos por el territorio así como referencias al aprovechamiento de los montes de la zona. De igual forma, existen varios estudios que proporcionan información sobre la administración del paisaje rural, aunque no sea aparentemente el tema principal de análisis ${ }^{82}$. Por su parte, Carmona Ruiz además de abundantes estudios sobre el reino de Sevilla y su territorio, recientemente ha publicado un trabajo sobre la utilidad económica de los espacios incultos de la Sierra Norte de Sevilla ${ }^{83}$. Para Granada Malpica Cuello sigue teniendo una excelente producción sobre las muchas actividades económicas como la explotación de la sal, ganadería, agricultura o analizando el paisaje y poblamiento nazari ${ }^{84}$. No hay que olvidar las diversas publicaciones de los resultados de varias reuniones científicas, donde se pone de relieve los diferentes métodos y recursos para estudiar los paisajes históricos,

\footnotetext{
77 Valor Piechotta, "Las fortificaciones de la Baja Edad Media en la provincia de Sevilla", pp. 687-700 y como coordinadora, Historia y arqueología de la Constancia medieval.

78 Ver nota 54.

79 Glick, Paisajes de conquista.

80 CARPIO DuEÑAS, "Evolución del paisaje y aprovechamientos económicos", pp. 87-121 y junto a TORRES MÁrquez, Evolución histórica del territorio de Madinat al-Zahra.

81 CóRdoba DE la Llave, “Actividades agropecuarias y explotación de los recursos naturales”, pp. 219-244; LÓPEz Rider, "Los molinos del río Monturque", pp. 145-156; Estudio sobre construcciones hidráulicas e industriales de Santaella (Córdoba); "Aportación al estudio de la hacienda del concejo de Córdoba", pp. 275-319; "La producción de carbón en el reino de Córdoba", pp. 819-858; y con VArela Romero y Díaz Hidalgo, "Los molinos de cubo de Montoro (Córdoba)", pp. 445-457.

82 Ruiz Povedano, "El "juzgado de términos, veredas y cañadas”", pp. 109-150; Pérez-EMBID WAMBA, "En el entorno rural de la Córdoba cristiana”, pp. 413-430; y aunque sin ceñirse en la Baja Edad Media, cabría incluir el trabajo de López Estudillo, "Paisaje y poblamiento en la Campiña de Córdoba", pp.259-277. 83 Carmona Ruiz, "El aprovechamiento de los espacios incultos", pp. 193-208.

${ }^{84}$ Malpica Cuello, "Una propuesta de análisis", pp. 9-28; "Poblamiento, agricultura y ganadería”, pp. 41-54; con García-Contreras Ruiz, “Asentamientos y explotación de la sal”, pp. 295-324 y de nuevo en solitario, Las últimas tierras de al-Ándalus.
} 
predominando la arqueología del paisaje ${ }^{85}$. En la zona gaditana, de nuevo hay que destacar los trabajos de Martín Gutiérrez acerca del paisaje rural. Prueba de ello, son las ya citadas Jornadas que organizó en 2009 y cuyos resultados fueron publicados en 2011, donde se pueden ver una gran diversidad de reflexiones sobre el estudio de los paisajes medievales andaluces ${ }^{86}$. No obstante, además de los trabajos que han sido mencionados anteriormente, en los últimos años ha desarrollado una bibliografía de gran importancia, donde ha centrado sus líneas de investigación en profundizar sobre la comarca de la Andalucía occidental, indagando acerca de los humedales y la importancia de los paisajes salubres. En este sentido, ha demostrado que eran espacios explotados con una gran vinculación al poblamiento asentado en sus proximidades, plasmando que no existía una marginalidad tan manifiesta como se ha supuesto hasta el momento. También ha mostrado la interacción entre sociedad y medio ambiente a través de las diversas actividades que el hábitat rural ha ido aplicando entre los siglos bajomedievales en la región jerezana ${ }^{87}$.

\section{Balance final y perspectivas de futuro}

Como se puede comprobar, en Andalucía son principales objetos de estudio la repoblación y reconquista para el periodo bajomedieval. Consecuencia directa de estos dos elementos temáticos es la aparición y mantenimiento de diversas perspectivas de investigación (poblamiento, propiedad y estructuras agrarias, articulación del territorio y vías de comunicación medievales, señoríos, órdenes militares, ámbito eclesiástico, concejos y sus alfoces, actividades industriales y mercantiles, demografía y sociedad, frontera o violencia tanto rural como urbana $)^{88}$.

Desde hace unos años se han venido renovando los enfoques de investigación. Como se comentó en las páginas precedentes, la reconquista y repoblación se investigan con otros enfoques cobrando protagonismo el paisaje. Esta renovación también llega a la historia medieval andaluza, se apuesta por los diferentes agentes de poder sobre el paisaje, destacando la sociedad rural y su influencia en el entorno físico. La naturaleza va ganando mayores adeptos, analizando la evolución del medio natural y su explotación, cobrando

\footnotetext{
85 Martín Civantos, Medio Ambiente y arqueología medieval; Malpica Cuello, Análisis de los paisajes históricos; Jiménez Puertas y Luca Mattei (eds.), El paisaje y su dimensión arqueológica; Jiménez Puertas y García-Contreras Ruiz (eds.), Paisajes históricos y Arqueología medieval, o Malpica Cuello (ed.), Zonas húmedas en Andalucía Medieval.

86 Martín Gutiérrez, El paisaje rural en Andalucía Occidental.

87 Martín GutiÉRrez, "Reflexiones en torno a los paisajes rurales en Jerez de la Frontera", pp. 175-193; "Interacción, sociedad y medio ambiente", pp. 103-130; Paisajes, ganadería y medio ambiente; "Paisajes palustres", pp. 15-49; "El aprovechamiento de humedales y marismas", pp. 121-147 y "Paisajes imaginados y paisajes reales", pp. 17-40.

${ }_{88}$ GARCíA FITz, "Conflictos jurisdiccionales, articulación territorial y construcciones militares", pp. 25-52; CARmona Ruz, Usurpaciones de tierras y derechos comunales y Borrero Fernández, "Violencia entre vecinos", pp. 145-158; CABRERA MuÑoz, "Usurpación de tierras y abusos señoriales en la Sierra cordobesa", pp. 33-84; RUfo YsERn, "Problemas de términos entre Carmona y Écija", pp. 363-386; "Usurpaciones de tierras y derechos comunales en Écija", pp. 449-496 y "Los jueces de términos en Écija, pp. 131-148.
} 
protagonismo el gradiente ecológico ${ }^{89}$. A través de la utilización de las fuentes escritas bajomedievales se va innovando con nuevas miradas hacia el paisaje y el balance sigue siendo positivo. Un ejemplo es el novedoso enfoque hacia los paisajes palustres, donde cobra vital importancia el concepto riparia, muy utilizado por el profesor Martín Gutiérrez y que como bien explica en uno de sus trabajos, este vocablo permite identificar "espacios vulnerables y propone interpretaciones ecosistémicas de las interacciones sociedad y medio ambiente" ${ }^{90}$. Desde una perspectiva arqueológica la situación es diferente, como indicara Alcázar Hernández en su revisión historiográfica de hace apenas unos años, en la mayoría de las actividades desarrolladas los resultados son parciales, muy centrados en el análisis de la cerámica y dedicados en su mayoría al periodo islámico, algo que Acién Almansa ya advirtió hace más de dos décadas ${ }^{91}$. No obstante, poco a poco se va introduciendo nuevas metodologías de estudio que contribuyen a elevar la calidad de manera muy clara el conocimiento sobre el poblamiento y paisajes rurales. Hoy día, la aplicación de las herramientas de geoprocesamiento SIG y el software que le acompaña, permiten reconstruir gráficamente y de la manera más fidedigna posible, el paisaje de los siglos bajomedievales de cualquier región. ${ }^{92}$ Asimismo, el desarrollo de la denominada arqueología experimental y la arqueometría, donde el trabajo de laboratorio es fundamental, ayudan a perfeccionar la investigación bajomedieval sobre la temática analizada. Desde análisis antracológicos, carpológicos, pasando por el estudio de las técnicas de elaboración de cerámica o de vidrio, y finalizando por el análisis de los materiales de producción o la detección de contaminaciones a lo largo de diversas épocas, son actividades que continuamente en países como Inglaterra, Francia o Italia se están desplegando desde hace bastante tiempo. Estos parámetros son las líneas futuras para el medievalismo hispano y andaluz, ya que con esa interdisciplinariedad benefician los resultados que se pueden obtener mostrando una vinculación muy fuerte las fuentes escritas, los restos arqueológicos y el trabajo de laboratorio ${ }^{93}$.

\footnotetext{
89 Pérez-Embid Wamba (coord.), La Andalucía medieval; Malpica Cuello, "El medio natural y el poblamiento medieval", pp. 141-162; Medio físico y poblamiento en el delta del Guadalfeo; MARTín GuTIÉRReZ, "Los espacios cultivados y los incultos", pp. 355-376; QuesADA QuesAda, El paisaje rural de la Campiña de Jaén o ARgente del CAstillo, "La utilización pecuaria de los baldíos andaluces", pp. 437-466; La ganadería medieval andaluza, y más reciente "El paisaje vegetal en el reino de Jaén", pp. 209-230.

90 Martín Gutiérrez, "El aprovechamiento de humedales y marismas", p. 124 y Hermon (dir.), Riparia dans l'Empire Romain.

91 AlCÁZAR HernáNDEZ, "Reflexiones y balance historiográfico", pp. 87-88.

92 López Rider, Santaella y el suroeste de la Campiña, donde se incluyen dos mapas en formato A2 y que plasman la realidad paisajística de esta región, recogiendo lugares habitados, despoblados, torres defensivas, caminos, puntos de agua y los diferentes aprovechamientos económicos del territorio. Otras reuniones y publicaciones: FERnÁNDEZ CACHO, "Nuevas tecnologías en la gestión de la información", pp. 169-210; Talbert y Unger, Cartography in antiquity and the Middle Ages y Mayoral Herrera y Celestino Pérez, Actas del V Simposio Internacional de Arquitectura de Mérida: Tecnologías de información geográfica y análisis arqueológico del territorio.

93 Entre muchos otros trabajos, son un buen ejemplo Córdoba de la Llave, Duckworth y Govantes Edwards, "Recipes and experimentation?", pp. 176-195; Ros, PUIG y RuAs, "Les denrées végétales dans le nord de la Catalogne", pp. 123-138; Alejandre SÁnchez, "Los morteros en la Edad Media", pp. 235-250 o MiLLSON, Experimentation and Interpretation.
} 
Con todo, la síntesis aquí plasmada permite valorar la adecuada evolución de las publicaciones que se han venido emprendiendo hasta la actualidad sobre un poblamiento y un paisaje de carácter rural. Son un elenco bibliográfico, que a pesar no estar aquí recogido en su totalidad, plasma los procesos metodológicos, las perspectivas de estudio y los resultados que se han venido logrando hasta hoy día. Sin duda se ha conseguido la revitalización de la investigación medieval andaluza a través de una metodología más completa, haciendo un adecuado uso de fuentes documentales y arqueología. Esto ha permitido que, hoy por hoy, se disfrute de estudios más completos, no solo orientados hacia el estudio de la organización del espacio territorial, el poblamiento o el paisaje, sino de otros muchos temas que con la metodología y herramientas indicadas, mejorará notablemente en el futuro para seguir profundizando en la Andalucía bajomedieval.

\section{Bibliografía citada}

Abellán PÉrez, Juan, "El despoblado de Beca”, Estudios de historia y arqueología medievales, 5-6 (1985-1986), pp. 361-368.

Abellán Pérez, Juan, “Aproximación al espacio rural jerezano en la Edad Media: la alquería de Margalihud”, Al-Ándalus Magreb: Estudios árabes e islámicos, 7 (1999), pp. 13-20.

Abellán Pérez, Juan, "Los orígenes de Vejer de la Frontera”, Estudios sobre patrimonio, cultura y ciencias medievales, 7-8 (2005-2006), pp. 7-18.

Acién Almansa, Manuel, Ronda y su Serranía en tiempo de los Reyes Católicos, Universidad de Málaga, 3 vols., 1979.

Actas del I Coloquio de Historia Medieval Andaluza, Monte de Piedad y Caja de Ahorros, Córdoba, 1982.

Actas del II Coloquio de Historia Medieval Andaluza: Hacienda y comercio, abril de 1981, Diputación provincial de Sevilla, Sevilla, 1982.

Actas del III Coloquio de Historia Medieval Andaluza: La sociedad medieval andaluza, grupos no privilegiados, Diputación Provincial de Jaén, Jaén, 1984.

Anasagasti Valderrama, Ana María y Rodríguez Liáñez, Laureano, El Libro de repartimiento de Medina Sidonia. Estudio y edición, Caja de Ahorros de Cádiz, Cádiz, 1987. Anasagasti Valderrama, Ana María y Rodríguez Liáñez, Laureano, Niebla y su tierra en la Baja Edad Media: historia y documentos, Diputación Provincial de Huelva, Huelva, 2 vols., 2006.

Andalucía. Medieval: Actas del I Congreso de Historia de Andalucía, diciembre de 1976, 2 vols., Monte de Piedad y Caja de Ahorros de Córdoba, Córdoba, 1978.

Andalucía Medieval: Actas del II Congreso de Historia de Andalucía, 1991, Junta de Andalucía, Conserjería de Cultura y Medio Ambiente y Obra Social y Cultural de Cajasur, tomos 4 y 5, Sevilla-Córdoba, 1994. 
Andalucía Medieval: Actas del III Congreso de Historia de Andalucía, diciembre de 2001, Obra Social y Cultural de Cajasur, tomos 5 y 6, Córdoba, 2003.

AlCÁzAR Hernández, Eva Ma " "La dinámica de un territorio: evolución del espacio rural de Jaén desde época romana hasta la repoblación castellana", Studia historica. Historia Medieval (ejemplar dedicado en memoria de José Luis Martín), 20-21 (2002-2003), pp. 105-161.

AlCÁZAR Hernández, Eva Ma, "Formación y articulación de un concejo fronterizo, Jaén en el siglo XIII", Arqueología y territorio medieval, 10-2 (2003), pp. 255-286.

AlCÁzar Hernández, Eva Ma , El Concejo de Jaén en la Baja Edad Media: Introducción al análisis del territorio y del poblamiento, tesis doctoral, Universidad de Jaén, 2004.

Alcázar Hernández, Eva Ma y Salvatierra Cuenca, Vicente, "La organización del poblamiento castellano en la Sierra de Segura: el caso de la aldea de Torres de Albanchez", Kalathos: revista del seminario de arqueología y etnología turolense, 24-25 (2005-2006), pp. 373-396.

Alcázar Hernández, Eva Ma "La ciudad fronteriza y su territorio: Jaén en la baja Edad Media", Beatriz Arízaga Bolumburu y Jesús Ángel Solórzano Telechea (eds.), La ciudad medieval y su influencia territorial, Instituto de Estudios Riojanos, Logroño, 2007, pp. 181-204.

Alcázar Hernández, Eva Ma ${ }^{\mathrm{a}}$, Aldeas y cortijos medievales de Jaén, IEG, Universidad de Jaén, 2008.

AlCÁZAR Hernández, Eva Ma "Reflexiones y balance historiográfico sobre el estudio del paisaje rural bajomedieval en España desde la Arqueología", Norba. Revista de Historia, vol. 25-26 (2012-2013), pp. 77-88.

AlCÁzAr Hernández, Eva Ma "'Las fortificaciones del concejo fronterizo de Jaén. Siglos XIII-XV", Isabel Cristina Ferreira Fernándes (coord.), Fortificaçoes e territorio na Península Ibérica e no Magreb (séculos VI a XVI), vol. 1, 2013, pp. 199-208.

Alejandre SÁnchez, Francisco Javier, "Los morteros en la Edad Media", La Técnica de la Arquitectura Medieval, Universidad de Sevilla, Sevilla, 2000, pp. 235-250.

Alijo Hidalgo, Francisco, "Castillos y lugares del Alfoz de Antequera en la Baja Edad Media”, Baetica: Estudios de arte, geografía e historia, 2-1 (1979), pp. 177-186.

Alijo Hidalgo, Francisco, Antequera y su tierra, 1410-1450: Libro de Repartimientos, Arguval D. L., Málaga, 1983.

Argente del Castillo, Carmen, "La utilización pecuaria de los baldíos andaluces (siglos XIII-XIV)", Anuario de Estudios Medievales, 20 (1990), pp. 437-466.

ARgente del CAStiLlo, Carmen, La ganadería medieval andaluza: siglos XIII-XVI (reinos de Jaén y Córdoba), Diputación Provincial de Jaén, Jaén, 2 vols., 1991.

Argente del Castillo, Carmen, "El paisaje vegetal en el reino de Jaén", Francisco Javier Pérez-Embid Wamba (coord.), La Andalucía medieval: Actas de las I Jornadas de Historia Rural y Medio Ambiente (Almonte, mayo de 2000), Universidad de Huelva, Huelva, 2002, pp. 209-230. 
Asenjo Sedano, Carlos, Guadix, la ciudad musulmana del siglo XVy su transformación en la ciudad neocristiana del siglo XVI, Diputación Provincial de Granada, Granada, 1983. Barrios Aguilera, Manuel, "La población de Loja a raíz de su incorporación al Reino de Castilla (según el padrón de 1491)”, Chronica Nova, 10 (1979), pp. 69-122.

Barrios Aguilera, Manuel, Los Repartimientos de Loja (1486-1510), Universidad de Granada, Granada, 1986.

Barrios Aguilera, Manuel, Libro de los repartimientos de Loja I, Universidad de Granada, Granada, 1988.

Bejarano Robles, Francisco, Los repartimientos de Álora y de Cártama, Aula de Cultura de Peña Malaguista, Málaga, 1971.

Bejarano Robles, Francisco, Los repartimientos de Málaga. Tomos I, II y III, Ayto. de Málaga, 1985.

Bejarano Robles, Francisco, Los repartimientos de Málaga V, Ayto. de Málaga, 2001.

Bejarano Robles, Francisco, Los repartimientos de Málaga IV, Ayto. de Málaga, 2004.

Bentto Ruano, Eloy, "La Reconquista. Una categoría histórica e historiográfica”, $\mathrm{Me}$ dievalismo, 12 (2002), pp. 91-98.

Borrero Fernández, Mercedes, "El concejo de Fregenal: población y economía del siglo XV”, Historia. Instituciones. Documentos, 5 (1978), pp. 113-168.

BorRero FernÁndez, Mercedes, "La población de Lora del Río de 1491 a 1534”, Archivo hispalense, tomo 64, 197 (1981), pp. 39-48.

Borrero Fernández, Mercedes, El mundo rural sevillano en el siglo XV: el Aljarafe y ribera, Diputación Provincial de Sevilla, Sevilla, 1983.

Borrero Fernández, Mercedes, "Situación demográfica de la Sierra Norte de Sevilla a fines de la Edad Media. Siglo XV-1534", Historia. Instituciones. Documentos, 25 (1998), pp. 43-72.

Borrero Fernández, Mercedes, "El poblamiento rural sevillano antes y después del Repartimiento", Manuel González Jiménez (coord.), Sevilla 1248. Congreso Internacional conmemorativo del 750 aniversario de la conquista de la ciudad de Sevilla por Fernando III, Rey de Castilla y León, Madrid, 2000, pp. 319-335.

Borrero Fernández, Mercedes, Mundo rural y vida campesina en la Andalucía medieval, Universidad de Granada, Granada, 2003.

Borrero Fernández, Mercedes, La organización del trabajo. De la explotación de la tierra a las relaciones laborales en el campo andaluz (siglos XIII-XVI), Universidad de Sevilla, Sevilla, 2003.

Borrero Fernández, Mercedes, "Violencia entre vecinos: las tensiones cotidianas en el ámbito rural medieval", Homenaje al prof. Eloy Benito Ruano, vol. 1, Universidad de Murcia, Murcia, 2010, pp. 145-158. 
CABrera Muñoz, Emilio, "Reconquista, repoblación y estructuras agrarias en el sector occidental de Los Pedroches (siglos XIII-XV)", Cuadernos de Historia. Anexos de Hispania, VII (1977), pp. 1-31.

Cabrera Muñoz, Emilio, "Usurpación de tierras y abusos señoriales en la Sierra Cordobesa durante los siglos XIV y XV", Actas I Congreso de Historia de Andalucía. Andalucía Medieval, II, Publicaciones del Monte de Piedad y Caja de Ahorros de Córdoba, 1978, pp. 33-84.

Cabrera Muñoz, Emilio (coord.), Andalucía entre Oriente y Occidente (1236-1492), Actas del V Coloquio Internacional de Historia Medieval de Andalucía, Diputación Provincial de Córdoba, Córdoba, 1988.

CABrera MuÑoz, Emilio, "La investigación sobre Andalucía medieval cristiana (19701990)", Andalucía Medieval: Actas del II Congreso de Historia de Andalucía, 1991, Junta de Andalucía, Conserjería de Cultura y Medio Ambiente y Obra Social y Cultural de Cajasur, tomo 4, Córdoba, 1994, pp. 121-155.

CABRERA MuÑoz, Emilio, "Reconquista, organización territorial y restauración eclesiástica en el reino de Córdoba en la época de Fernando III", Fernando III y su época, Actas de las IV Jornadas Nacionales de Historia Militar, Diputación Provincial de Sevilla, Sevilla, 1995, pp. 313-334.

CABrera Muñoz, Emilio, "Notas sobre la conquista y la organización territorial del reino de Córdoba en el siglo XIII", Medievo Hispano. Estudios in memoriam del Prof. D. Lomax, SEEM, Madrid, 1995, pp. 83-100.

CABrera MuÑoz, Emilio, "Reflexiones sobre los repartimientos y la repoblación de Andalucía”, Sevilla 1248: Congreso Internacional conmemorativo del 750 aniversario de la con- quista de la ciudad de Sevilla por Fernando tercero, rey de Castilla, Sevilla, Real, 27 de noviembre de 1998, Ayuntamiento-Fundación Ramón Areces, Sevilla, 2000 pp. 303-318. CABrera MuÑoz, Emilio, “Tópicos y realidades sobre la organización de Andalucía tras la reconquista", Antonio Malpica Cuello, Rafael Gerardo Peinado Santaella y Adela Fábregas García (coords.), Historia de Andalucía: VII Coloquio “¿Qué es Andalucía?. Una revisión histórica desde el Medievalismo”, 2009, Universidad de Granada, Granada, 2010, pp. 179-202.

CABrera MuÑoz, Emilio, "Algunos datos e ideas sobre el Repartimiento de Córdoba", Josefina Mutge Vives, Roser Salicrú i Lluch y Carles Vela i Aulesa (coords.), La Corona catalanoaragonesa, l'Islam i el món mediterrani: estudis d'història medieval en homenatge a la Doctora $M^{a}$ Teresa Ferrer y Mallol, CSIC, Madrid, 2013, pp. 141-148.

Cabrera Muñoz, Emilio et alii, Orígenes históricos de Villafranca de Córdoba, Universidad de Córdoba y Ayuntamiento de Villafranca, 2013.

CABrera Muñoz, Emilio, "Repoblación y señoríos en Andalucía (siglos XIII-XIV)", Beatriz Arízaga Bolumburu et alii (eds.), Mundos medievales: espacios, sociedades y poder: homenaje al profesor José Ángel García de Cortázar y Ruiz de Aguirre, vol. 2, 2014, pp. 1109-1124. 
Cabrillana, Nicolás, El problema de la tierra en Málaga. Pueblos desaparecidos, Unicaja, Málaga, 1993.

Calero Palacios, $\mathrm{M}^{\mathrm{a}}$ del Carmen, El apeo y repartimiento de Cenes de la Vega. Edición y estudio de algunos aspectos, Universidad de Granada, Granada, 1987.

Calero Palacios, $\mathrm{M}^{\mathrm{a}}$ del Carmen, El libro de repartimiento de Almuñécar: estudio y edición, Universidad de Granada, Granada, 2009.

Carmona Ruiz, $\mathrm{M}^{\mathrm{a}}$ Antonia, Usurpaciones de tierras y derechos comunales en Sevilla y "su tierra" durante el siglo XV, Ministerio de Agricultura, Pesca y Alimentación, Madrid, 1995.

Carmona Ruiz, Ma Antonia, "El aprovechamiento de los espacios incultos en la Andalucía Medieval: el caso de la Sierra Norte de Sevilla", Emilio Martín Gutiérrez (coord.), El paisaje rural en Andalucia Occidental durante los siglos bajomedievales: actas de las I Jornadas Internacionales sobre paisajes rurales en época medieval, Cádiz, abril de 2009, Universidad de Cádiz, Cádiz, 2011, pp. 193-208.

CARPio Dueñas, Juan Bautista, La tierra de Córdoba. El dominio jurisdiccional de la ciudad durante la Baja Edad Media, Universidad de Córdoba y Obra Social y Cultural de Cajasur, Córdoba, 2000.

CARPIo DueÑas, Juan Bautista, "Evolución del paisaje y aprovechamientos económicos en la falda de la sierra cordobesa (siglos XIII-XV)", Meridies. Revista de Historia Medieval, 9 (2011), pp. 87-121.

Carpio Dueñas, Juan Bautista y Torres Márquez, Martín, Evolución histórica del territorio de Madinat al-Zahra 1236-2009, Junta de Andalucía, Sevilla, 2014.

CARriazo Rubio, Juan Luis, "La conquista cristiana. La cuestión del Algarbe: Arroyomolinos de León", José Manuel Almonte Jurado y Juan Antonio Márquez Domínguez (coords.), Historia de la provincia de Huelva, vol. 1, Mediterráneo D. L., Huelva-Madrid, 1999, pp. 241-256.

CARriazo Rubio, Juan Luis, "Fronteras y fortificaciones en Andalucía Occidental durante la Baja Edad Media”, Juan Aurelio Pérez Macías (coord.), El territorio medieval: II Jornadas de Cultura Islámica, Almonaster la Real 2001, Universidad de Huelva, 2002, pp. 59-97.

Carriazo Rubio, Juan Luis, "Las fortificaciones del bajo Guadiana (siglos XIII-XV)", Francisco Toro Ceballos y José Rodríguez Molina (coords.), Funciones de la red castral fronteriza: homenaje a don Juan Torres Fontes, Alcalá la Real, Diputación Provincial de Jaén, Jaén, 2004, pp. 81-94.

Carriazo Rubio, Juan Luis, Huelva, tierra de castillos, Diputación Provincial de Huelva, Huelva, 2004.

Collantes de Terán SÁnchez, Antonio, Sevilla en la Baja Edad Media: la ciudad y sus hombres, Ayto. de Sevilla, 1977. 
Collantes de Terán SÁnchez, Antonio, "Nuevas poblaciones del siglo XV en el reino de Sevilla", Cuadernos de Historia (Anexos de la Revista Hispania), 7 (1977), pp. 283-336. Collantes de Terán SÁnchez, Antonio, "Los padrones militares de la Andalucía bajomedieval como fuentes demográficas", Actas I Congreso de Historia de Andalucía. Andalucía Medieval, Caja de Ahorros y Monte de Piedad de Córdoba, Córdoba, vol. 1, 1978, pp. 287-294.

Collantes de Terán SÁnchez, Antonio, "Evolución demográfica de la Andalucía bética (siglos XIV-XV)", Actas I Coloquio de Historia de Andalucía, Andalucía Medieval, Caja de Ahorros y Monte de Piedad de Córdoba, Córdoba, 1979, pp. 21-33.

Collantes de Terán SÁnchez, Antonio, "Los efectivos humanos", Historia de Andalucía, tomo III, Cupsa-Planeta, Barcelona, 1980, pp. 75-98.

Collantes de Terán SÁnchez, Antonio, “Andalucía I. La investigación sobre Andalucía en el periodo Bajomedieval”, Cristina Segura Graíño (ed.), Presente y futuro de la Historia Medieval en España: Actas de las I Jornadas sobre la investigación medieval en las comunidades autónomas, 1988, Universidad Complutense de Madrid, Madrid, 1990, pp. 221-236.

Collantes de Terán SÁnchez, Antonio, "Ciudad y territorio rural en la Andalucía medieval”, Beatriz Arízaga Bolumburu y Jesús Ángel Solórzano Telechea (eds.), La ciudad medieval y su influencia territorial, Instituto de Estudios Riojanos, Logroño, 2007, pp. 19-54.

Córdoba de la Llave, Ricardo, “Almodóvar del Río en la Edad Media”, Almodóvar del Río. Apuntes Históricos, Ayto. de Almodóvar del Río (Córdoba), 1991, pp. 45-69. Córdoba de la Llave, Ricardo, "El hábitat de Teba (Santa Cruz, Córdoba) en época medieval", Arte, arqueología e historia, 12 (2005), pp. 102-110.

CóRdoba DE LA Llave, Ricardo, “Actividades agropecuarias y explotación de los recursos naturales del término de Villafranca a fines de la Edad Media", Emilio CABrera MuÑoz et alii, Orígenes históricos de Villafranca de Córdoba, Universidad de Córdoba y Ayto. de Villafranca, 2013, pp. 219-244.

Córdoba de la Llave, Ricardo, "El castillo de Castro el Viejo", Ricardo Córdoba de la Llave, José Antonio Morena López, Carlos Márquez Moreno y Ángel Ventura-Villanueva (eds.), Torreparedones. Investigaciones arqueológicas (2006-2012), Universidad de Córdoba-Ayto. de Baena, 2014, pp. 131-139.

Córdoba de la Llave, Ricardo, "Valenzuela y su territorio en la Edad Media", Historia de Valenzuela: Actas de Jornadas, Diputación Provincial de Córdoba, Córdoba, 2015, pp. 173-201.

Córdoba de la Llave, Ricardo, Duckworth. N. Chloe y Govantes Edwards, David, "Recipes and experimentation? The transmission of gallsmaking techniques in Medieval Iberia”, Journal of Medieval Iberian Studies, 8:2 (2016), pp. 176-195. 
CREsSiER, Patrice, "Las fortalezas musulmanas de la Alpujarra (provincias de Granada y Almería) y la división político-administrativa de la Andalucía oriental", Arqueología espacial (ejemplar dedicado a Época romana y medieval), 5 (1984), pp. 179-200.

CRESSIER, Patrice, "La château et la division territoriale dans l'Alpujarra médiévale du hisn à la Ta'a", Mélanges de la Casa de Velázquez, 20 (1984), pp. 115-144.

CREsSier, Patrice, "Dalías y su territorio: un grupo de alquerías musulmanas de la baja Alpujarra (Almería)", Patrice Cressier (coord.), Estudios de arqueología medieval en Almería, Instituto de Estudios Almerienses, Almería, 1992, pp. 89-120.

CRessier, Patrice, "El patrimonio almohade de Almería", José Ramírez del Río, Magdalena Valor Piechotta y José Luis Villar Iglesias (coords.), Los almohades, su patrimonio arquitectónico y arqueológico en el sur de al-Ándalus, Junta de Andalucía, Sevilla, 2004, pp. 91-102.

Cressier, Patrice, "Vigilar, proteger, habitar. A propósito de las torres en el ámbito rural andalusí", Pierre Moret y $\mathrm{M}^{\mathrm{a}}$ Teresa Chapa Brunet (coords.), Torres, atalayas y casas fortificadas: explotación y control del territorio en Hispania (s. III a. de C.-s. I d. de C.), Universidad de Jaén, Jaén y Casa de Velázquez, Madrid, 2004, pp. 209-214. Del Pino García, José Luis, "Monturque en la Edad Media", Historia de Monturque de los orígenes al final de la Edad Media, Ayto. de Monturque (Córdoba), 1993, pp. 175-344. Del Pino García, José Luis y Carpio Dueñas, Juan Bautista, "Los Pedroches y el despoblado medieval de Cuzna", Antiquitas, 9 (1998), pp. 177-200.

Del Pino García, José Luis, "De Castillo Anzur a Puente don Gonzalo: la ordenación social de un territorio campiñés en la Edad Media", Enrique Soria Mesa (coord.), Puente Genil, pasado y presente, Universidad de Córdoba, Córdoba, 2002, pp. 243-260.

Del Pino García, José Luis, "Poblamiento y organización social en la campiña de Córdoba durante la Edad Media", Estudios de historia de España, 6 (2004), pp. 41-80. Del Pino García, José Luis, "Luque en la Baja Edad Media", En la España medieval, 33 (2010), pp. 203-232.

Edwards, John, Christian Cordoba: the city and its region in the late Middle Ages, Cambridge, 1982.

Escobar Camacho, José Manuel, "El reino de Córdoba en la época de Alfonso X: tierras realengas y señoriales", Boletín de la Real Academia de Córdoba, 108 (1985), pp. 105-119.

Escobar Camacho, José Manuel, "La Rambla durante la Edad Media", La Rambla. Apuntes para su historia, Diputación Provincial de Córdoba, Córdoba, 1991, pp. 35-60. Escobar Camacho, José Manuel, "La campiña de Córdoba en la Baja Edad Media: Delimitación y organización espacial", Ifigea, 9 (1993), pp. 57-75.

Escobar Camacho, José Manuel, "Benamejí durante los siglos bajomedievales", Actas de las primeras jornadas de la Real Academia de Córdoba en Benamejí, Real Academia de Córdoba, Córdoba, 1998, pp. 41-54. 
Escobar Camacho, José Manuel, "Las cuevas de Carchena: usurpaciones de tierras y pleitos sobre su término a mediados del siglo XIV", Crónica de Córdoba y sus pueblos, 7 (2001), pp. 11-26.

Escobar CAMACHO, José Manuel, "De la Córdoba islámica a la cristiana. Conquista, repoblación y repartimiento urbano", Al-Mulk: anuario de estudios arabistas, 6 (2006), pp. 69-94. Escobar CAmacho, José Manuel, "La Córdoba bajomedieval (siglos XIII-XV): el origen de la ciudad cristiana", José Manuel Escobar Camacho, Antonio López Ontiveros y Juan Francisco Rodríguez Neila (coords.), La ciudad de Córdoba: origen, consolidación e imagen, Universidad de Córdoba, Córdoba, 2009, pp. 83-132.

Escobar Camacho, José Manuel, Historia de Hornachuelos en la Baja Edad Media (siglos XIII-XV), Séneca, D. L., Córdoba, 2010.

FERnÁNDEZ CACHO, Silvia, "Nuevas tecnologías en la gestión de la información de patrimonio arqueológico en Andalucía”, José Clemente Martín de la Cruz y Agustín María Lucena Martín (eds.), Informática aplicada a la investigación y la gestión arqueológicas: actas del I Encuentro Internacional, Córdoba (5-7 de mayo de 2003), Universidad de Córdoba, Córdoba, 2004, pp. 169-210.

Franco Silva, Alfonso, "Datos demográficos y organización municipal de las villas almerienses de los Vélez (1492-1540)", Gades, 5 (1980), pp. 85-112.

Franco SiLva, Alfonso, "La organización social del territorio gaditano entre los siglos XIII al XV”, Almoraima, 9 (1993), pp. 313-326.

Franco Silva, Alfonso, "Notas sobre la villa de Alarcón y su tierra en la Baja Edad media", Scripta: estudios en homenaje a Elida García García, Universidad de Oviedo, Oviedo, 1998, pp. 187-206.

Franco Silva, Alfonso, "Población y reparto de la propiedad en Chipiona en el primer cuarto del siglo XVI", Beatriz Arízaga Bolumburu et alii (eds.), Mundos medievales: espacios, sociedades y poder: homenaje al profesor José Ángel García de Cortázar y Ruiz de Aguirre, vol. 2, Universidad de Cantabria, Santander, 2014, pp. 1319-1338.

Galán Sánchez, Ángel y Peinado Santaella, Gerardo Rafael, La repoblación de la costa malagueña: los repartimientos de Marbella y Estepona, Diputación Provincial de Málaga, Málaga, 2007.

García de Cortázar, José Ángel et alii, Organización social del espacio en la España Medieval. La Corona de Castilla en los siglos VIII a XV. Ariel, Barcelona, 1985.

García de Cortázar, José Ángel (ed.), Del Cantábrico al Duero. Trece estudios sobre organización social del espacio en los siglos VIII al XIII, Universidad de Cantabria, Santander, 1999.

GARCÍA DE CORTÁzAR, José Ángel "Sociedad rural y medio físico en la España Medieval: Transformaciones del entorno físico en el Reino de Castilla en los siglos VIII al XV", Javier Pérez-Embid Wamba (coord.), La Andalucía medieval: Actas de las I Jornadas de Historia Rural y Medio Ambiente (Almonte, mayo de 2000), Universidad de Huelva, Huelva, 2002, pp. 15-42. 
García de Cortázar, José Ángel Sociedad y organización del espacio en la España medieval, Universidad de Granada y Universidad de Valencia, 2004.

García de Cortázar, José Ángel "Sociedad rural y entorno físico: las modificaciones del paisaje en la Castilla medieval", Flocel Sabaté i Curull (coord.), Natura i desenvolupament. El medi ambient a l'Edat Mitjana, Pagès Editors, Lleida, 2007, pp. 251-274. García Fernández, Manuel, "La carta puebla del castillo de Cote. Estudio y edición", Archivo Hispalense, 214 (1987), pp. 57-68.

García Fernández, Manuel, "Nuevos datos sobre la repoblación del sector sur de la campiña sevillana durante el siglo XIV", Emilio Cabrera Muñoz (coord.), Andalucía entre Oriente y Occidente (1236-1492). Actas del V Coloquio Internacional de Historia Medieval de Andalucía, Diputación Provincial de Córdoba, Córdoba, 1988, pp. 145-160. GARCÍA FERnÁNDEZ, Manuel, La campiña sevillana y la frontera de Granada (siglos XIIIXV): estudios sobre poblaciones de la Banda Morisca, Fundación Contsa, Sevilla, 2005. García Fernández, Manuel, "Gibraltar, conquista y repoblación (1309-1310)", Medievalismo, 19 (2009), pp. 155-169.

García Fernández, Manuel, "Alfonso XI y la villa de Teba. La Carta Puebla de 1330. Estudio y edición", M $M^{\mathrm{a}}$ Isabel del Val Valdivieso y Pascual Martínez Sopena (coords.), Castilla y el mundo feudal: homenaje al profesor Julio Valdeón, vol. 1, Conserjería de Cultura y Turismo y Universidad de Valladolid, Valladolid, 2009, pp. 203-213.

García Fitz, Francisco, "Conflictos jurisdiccionales, articulación territorial y construcciones militares a fines del siglo XIII en el alfoz de Sevilla: la sierra de Aroche", Archivo Hispalense, tomo 75, 230 (1992), pp. 25-52.

García Fitz, Francisco, "La Reconquista: un estado de la cuestión", Clio \& Crimen: Revista del Centro de Historia del Crimen de Durango, 6 (2009), pp. 142-215.

García Fitz, Francisco, La Reconquista, Universidad de Granada, Granada, 2010.

García Pardo, Manuela, "Los estudios de población y poblamiento en Almería (siglos XV y XVI). Estado de la cuestión", Francisco Toro Ceballos y José Rodríguez Molina (coords.), VI Estudios de Frontera. Población y poblamiento, homenaje a Manuel González Jiménez, Diputación Provincial de Jaén, Jaén, 2007, pp. 279-296.

García Sanjuán, Alejandro, "La conquista de Niebla por Alfonso X", Historia. Instituciones. Documentos, 27 (2000), pp. 89-112.

García Sanjuán, Alejandro, Hasta que Dios herede la tierra: los bienes habices en Al-Ándalus (siglos X-XV), Mergablum, Huelva, 2002.

García SAnJuÁn, Alejandro, "Poblamiento y organización del territorio onubense durante el periodo andalusí (siglos VIII-XIII)", Andalucía Medieval. Actas del III Congreso de Historia de Andalucía, 2001, Caja de Ahorros y Monte de Piedad de Córdoba, Córdoba, vol. 5, 2003, pp. 89-106.

García SAnJuÁn, Alejandro, Evolución histórica y poblamiento del territorio onubense durante la época andalusí (siglos VIII-XIII), Universidad de Huelva, Huelva, 2003. 
Glick, Thomas F., Islamic and Christian Spain in the early Middle Ages, Princeton University Press, 1979.

GLICK, Thomas F., Paisajes de conquista: cambio cultural y geográfico en la España medieval, Universitat de Valencia, Valencia, 2007.

GonzÁlez JimÉnez, Manuel, La repoblación de la zona de Sevilla en el siglo XIV. Estudio y documentación, Universidad de Sevilla, Sevilla, 1975.

González Jiménez, Manuel y GonzÁlez Gómez, Antonio, El Libro de repartimiento de Jerez de la Frontera: estudio y edición, Instituto de Estudios Gaditanos, Cádiz, 1980.

González Jiménez, Manuel, "Repartimiento de Carmona: estudio y edición”, Historia. Instituciones. Documentos, 8 (1981), pp. 59-84.

GonzÁlez Jiménez, Manuel y Bartolomé Somoza, Enrique, Carta-puebla otorgada a el Gran Puerto de Santa María por Alfonso X el Sabio, Ayto. de El Puerto de Santa María, 1981.

GonzÁlez JimÉnez, Manuel, "La obra repobladora de Alfonso X en las tierras de Cádiz”, Cádiz en el siglo XIII, Universidad de Cádiz, Cádiz, 1983, pp. 7-19.

GonzÁlez Jiménez, Manuel, “Andalucía Bética”, José Ángel García de Cortázar et alii, Organización social del espacio en la España Medieval. La Corona de Castilla en los siglos VIII a XV, Ariel, Barcelona, 1985, pp. 163-194.

GonzÁlez Jiménez, Manuel, “Conquista y repoblación de Alcalá de Guadaira”, Actas I Jornadas de Historia de Alcalá de Guadaira, Fundación Municipal de Cultura, Alcalá de Guadaira, 1987, pp. 135-158.

GonZÁlez JimÉneZ, Manuel, “Reconquista y repoblación del Occidente peninsular”, Actas de las II Jornadas Luso-Espanholas da História Medieval, vol. I, Porto, Universidad, 1987, pp. 455-489.

GonzÁlez JimÉnez, Manuel, "Población y repartimiento de Écija”, Homenaje al prof. J. Torres Fontes, vol. I, Universidad de Murcia, Murcia, 1987, pp. 691-712.

GonZÁlez Jiménez, Manuel, "Repartimientos andaluces del siglo XIII, perspectiva de conjunto y problemas", Historia. Instituciones. Documentos, 14 (1987), pp. 103-122.

GonZÁlez JimÉnEz, Manuel, "Repoblación y repartimiento de Écija”, Actas de I Congreso sobre Historia de Écija, tomo I, Ayto. de Écija, 1988, pp. 337-365.

GonzÁlez Jiménez, Manuel, En torno a los orígenes de Andalucía. La repoblación del siglo XIII, Universidad de Sevilla, Sevilla, 1988 (2 $2^{\text {a ed.). }}$

Gonzélez Jiménez, Manuel, "Poblamiento y frontera en Andalucía (ss. XIII-XV)", Revista de la Facultad de Geografía e Historia, 4 (1989), pp. 207-224.

GonzÁlez JimÉnEz, Manuel, "Los ritmos de la repoblación: el reino de Sevilla en vísperas de la conquista de Niebla", Miguel Ángel Ladero Quesada, Vicente Ángel Álvarez Palenzuela y Julio Valdeón Baruque (coords.), Estudios de Historia Medieval: Homenaje a Luis Suárez, Universidad de Valladolid, Valladolid, 1991, pp. 215-227. 
GonzÁlez Jiménez, Manuel, Diplomatario andaluz de Alfonso X, El Monte: Caja de Huelva y Sevilla, 1991.

GonzÁLez JimÉnez, Manuel, "La investigación en Historia Medieval de Andalucía", Medievalismo, 1 (1991), pp. 107-124.

GonZÁLez JimÉnez, Manuel, "Del Duero al Guadalquivir: repoblación, despoblación y crisis en la Castilla del siglo XIII", Despoblación y Colonización del Valle del Duero. Siglos VIII-XX. IV Congreso de Estudios Medievales, Fundación Sánchez Albornoz, Ávila, 1995, pp. 209-224.

GonzÁLez JimÉnez, Manuel, "Poblamiento en la Baja Andalucía: de la repoblación a la crisis (1250-1340)", Europa en los umbrales de la crisis, 1250-1350. Actas de la XIII Semana de Estudios Medievales, Gobierno de Navarra, Estella, 1995, pp. 63-86.

GonzÁlez JimÉnez, Manuel, "La obra repobladora de Fernando III en Jaén y Córdoba", Fernando III y su época, Actas de las IV Jornadas Nacionales de Historia Militar, Diputación Provincial de Sevilla, Sevilla, 1995, pp. 287-312.

GonzÁlez Jiménez, Manuel, "El repartimiento de Carmona", Archivo Hispalense (ejemplar dedicado al I Congreso de Historia de Carmona: Edad Media. Actas), tomo 80, 243-245 (1997), pp. 199-224.

GonZÁlez JimÉnez, Manuel, Sevilla 1248. Congreso Internacional conmemorativo del 750 aniversario de la conquista de la ciudad de Sevilla por Fernando III, Rey de Castilla y León, Sevilla, 23-27 de noviembre de 1998, Centro de Estudios Ramón Areces, Madrid, 2000.

GonzÁlez Jiménez, Manuel, “¿Re-conquista? Un estado de la cuestión”, Eloy Benito Ruano (coord.), Tópicos y realidades de la Edad Media, vol. 1, Real Academia de la Historia, Madrid, 2000, pp. 155-178.

GonzÁlez Jiménez, Manuel (coord.), Repartimiento de El Puerto de Santa María, Universidad de Sevilla, Sevilla, 2002.

GonZÁLez JimÉnez, Manuel, "Sobre la ideología de la Reconquista: realidades y tópicos", José Ignacio de la Iglesia Duarte y José Luis Martín Rodríguez (coords.), Memoria, mito y realidad en la historia medieval: XIII Semana de Estudios Medievales, Nájera, 2003, pp. 151-170.

GonzÁlez JimÉnez, Manuel, "Alfonso X, repoblador", Manuel González Jiménez (coord.), El mundo urbano en la Castilla del siglo XIII, Fundación El Monte, Sevilla, 2006, vol. 1, pp. 17-32.

GonZÁlez JimÉNEZ, Manuel et alii, "Las villas nuevas de Andalucía en la Edad Media (siglos XIII-XVI)", Boletín Arkeolan (Pascual Martínez Sopena y $\mathrm{M}^{\mathrm{a}}$ Mercedes Urteaga Artigas (coords.). Ejemplar dedicado a: Las villas nuevas medievales del suroeste europeo. De la fundación medieval al siglo XXI: análisis histórico y lectura contemporánea), 14 (2006), pp. 349-370.

GonZÁlez JimÉnez, Manuel, "La Reconquista: realidad y leyenda", Cátedra Jorge Juan: ciclo de conferencias, Universidade da Coruña, La Coruña, 2007, pp. 131-146. 
GonzÁlez JimÉnez, Manuel, La repoblación del reino de Sevilla en el siglo XIII, Universidad de Granada y Universidad de Sevilla, Granada y Sevilla, 2008.

GonzÁlez JimÉnez, Manuel, “QQué es Andalucía?: Una revisión histórica desde el medievalismo", Boletín de la Real academia Sevillana de Buenas Letras: Minervae Baeticae, 38 (2010), pp. 9-36.

GonzÁlez Jiménez, Manuel, “Constantina en el siglo XIII”, Magdalena Valor (coord.), Historia y arqueología de la Constantina medieval, Universidad de Sevilla, Sevilla, 2011, pp. 35-50.

GonZÁlez JimÉNEZ, Manuel, “La repoblación de Andalucía: inmigrantes y repoblación”, Cuadernos de historia de España (ejemplar dedicado al Homenaje de María Estela González de Fauve), 85-86 (2011-2012), pp. 295-302.

GonzÁlez JimÉnEz, Manuel, "Los inicios de la repoblación de la Sierra de Huelva en el siglo XIII", Boletín de la Real academia Sevillana de Buenas Letras: Minervae Baeticae, 41 (2013), pp. 365-374.

González Jiménez, Manuel, Los repartimientos de Vejer de la Frontera (1288-1318), Real Sociedad Económica de Amigos del País de Vejer, D. L., Cádiz, 2014.

GonzÁlez Jiménez, Manuel, La repoblación de la zona de Sevilla durante el siglo XIV, Universidad de Sevilla, Sevilla, 2015.

GonzÁlez, Julio, Reinado y diplomas de Fernando III, 3 vols., Monte de Piedad y Caja de Ahorros, Córdoba, 1980-1986.

GonzÁlez, Julio, Repartimiento de Sevilla. Estudio y edición, Área de Cultura, Ayto. de Sevilla, 1991.

González, Julio, Las conquistas de Fernando III en Andalucía, Maxtor, Valladolid, 2006 ( $1^{\mathrm{a}}$ ed. 1946 en revista Hispania, núm. XXV).

Grima Cervantes, Juan, La Tierra de Mojácar y la comarca del río de Aguas: desde su conquista por los Reyes Católicos hasta la conversión de los mudéjares, 1488-1505, Ayto. de Mojácar, 1987.

GuICHARD, Pierre, Al-Ándalus: estructura antropológica de una sociedad islámica en occidente, Universidad de Granada, Granada, 1998 (2a Ed.).

Guichard, Pierre, De la expansión árabe a la Reconquista: esplendor y fragilidad de al-Ándalus, Fundación El Legado Andalusí, Granada, 2002.

Guichard, Pierre, "Córdoba, de la conquista musulmana a la conquista cristiana", Awraq, 7 (2013), pp. 5-24.

Hermon, Ella (dir.), Riparia dans l'Empire Romain pour la définition du concept, Actes des Journées d'étude de Québec, 29-31 Octobre 2009, BAR International Serie 2066, Oxford, 2010.

Jiménez Puertas, Miguel, El poblamiento del territorio de Loja en la Edad Media, Universidad de Granada, Granada, 2002. 
Jiménez Puertas, Miguel y Mattei, Luca (eds.), El paisaje y su dimensión arqueológica. Estudios sobre el sur de la Península Ibérica en la Edad Media, Alhulia, Granada, 2010. Jiménez Puertas, Miguel y García-Contreras Ruiz, Guillermo (eds.), Paisajes históricos y Arqueología medieval, Alhulia, Granada, 2011.

Ladero Quesada, Miguel Ángel, "La población de Andalucía en el siglo XV. Nota provisional", Anuario de Historia Económica y Social, 2 (1969-1972), pp. 479-496.

LADERo QuesadA, Miguel Ángel, "Datos demográficos sobre los musulmanes de Granada y Castilla en el siglo XV", Anuario de Estudios Medievales, 8 (1972-1973), pp. 481-490.

Ladero Quesada, Miguel Ángel y GonZÁlez JimÉnez, Manuel, "La población en la frontera de Gibraltar y el repartimiento de Vejer (siglos XIII y XV)", Historia. Instituciones. Documentos, 4 (1977), pp. 199-316.

Ladero Quesada, Miguel Ángel, "La investigación histórica sobre la Andalucía medieval, en los últimos veinticinco años (1951-1976)", Andalucía medieval: actas del I Congreso de Historia de Andalucía, Córdoba, diciembre de 1976, vol. 1, Montes de Piedad y Caja de Ahorros, Córdoba, 1978, pp. 217-250.

Ladero Quesada, Miguel Ángel, "Las ciudades de Andalucía occidental en la Baja Edad Media. Aspectos poblacionales y urbanísticos", Jornadas de Historia Medieval Andaluza, Ayto. de Jaén, 1984, pp. 159-295.

Ladero Quesada, Miguel Ángel, Granada después de la conquista. Repobladores y mudéjares, Diputación provincial de Granada, Granada, 1988.

LADERo QuesadA, Miguel Ángel, “¿Es todavía España un enigma histórico?”, Lecturas sobre la España histórica, Real Academia de la Historia, Madrid, 1998, pp. 317-431.

Ladero Quesada, Miguel Ángel, “Andalucía en la Baja Edad Media. Tiempos, trabajos y perspectivas de la investigación”, Josefa Feria Martín y Manuel José de Lara Ródenas (coords.), La historia de la provincia de Huelva: balance y perspectiva. Actas del I Encuentro sobre bibliografia: La Investigación Histórica en la Provincia de Huelva, 2002, Diputación Provincial de Huelva, Huelva, 2007, pp. 21-78.

Ladero Quesada, Miguel Ángel, "La población de reinos y ciudades en la baja edad media española (de finales del siglo XIII a comienzos del XVI)", Boletín de la Real Academia de la Historia, tomo 211, 1 (2014), pp. 37-78.

León MuÑoz, Alberto, "Evolución arquitectónica de la fortaleza de Aguilar de la frontera (Córdoba)", Anales de Arqueología cordobesa, 7 (1996), pp. 209-232.

León MuÑoz, Alberto, El castillo de Aguilar de la Frontera: interpretación desde la arqueología, Ayto. de Aguilar de la Frontera (Córdoba), 1998.

LEÓN MuÑoz, Alberto, "Los castillos del reino de Córdoba: revisión historiográfica y perspectivas actuales", Anales de Arqueología cordobesa, 10 (1999), pp. 291-336.

León Muñoz, Alberto, Las fortalezas de Belalcázar. Análisis arqueológico de su arquitectura (s. IX-XIX), Diputación de Córdoba, Delegación de Cultura, Córdoba, 2003. 
León MuÑoz, Alberto, "Las torres del homenaje como referentes del paisaje político bajomedieval. El reino de Córdoba", Paisaje y fortificación. Congreso Internacional sobre Fortificaciones, Ayto. de Alcalá de Guadaira, 2006, pp. 81-90.

LeÓN MuÑoz, Alberto, "Investigación castellológica e intervención arquitectónica: Belalcázar y el ejemplo cordobés", Simposio Internacional "Arquitectura Fortificada": conservación, restauración y uso de los castillos, Fundación del Patrimonio Histórico de Castilla y León, Valladolid, 2006, pp. 51-90.

León MuÑoz, Alberto, "Documentos emergentes, monumentos elocuentes. Las fortificaciones medievales de Córdoba (siglos VIII-XV)", Andalucía en la Historia, 27 (2010), pp. 76-81.

LeÓn MuÑoz, Alberto, "Las fortificaciones castellanas en el siglo XV en el reino de Córdoba", Francisco Cabezas Pérez y Alberto León Muñoz (coords.), Actas del I Jornadas de Fortificaciones Medievales: El sur de Córdoba, Ayto. de Aguilar de la Frontera (Córdoba), 2012, pp. 59-112.

LeÓn MuÑoz, Alberto, "Las fortificaciones de la Córdoba Almohade", Isabel Cristina Ferreira Fernándes (coord.), Fortificaçoes e territorio na Península Ibérica e no Magreb (séculos VI a XVI), vol. 1, Colibri, Lisboa, 2013, pp. 337-354.

Lomax, Derek, "La conquista de Andalucía a través de la historiografía europea de la época", Emilio Cabrera Muñoz (coord.), Andalucía entre Oriente y Occidente (12361492). Actas del V Coloquio Internacional de Historia Medieval de Andalucía, Diputación Provincial de Córdoba, Córdoba, 1988, pp. 37-50.

LóPez De CocA, José Enrique, "Bezmiliana, un despoblado en tierras malagueñas (siglos XV-XVI)", Cuadernos de Estudios Medievales, I (1973), pp. 33-62.

LÓPEZ DE COCA, José Enrique, "Poblamiento y frontera en el obispado de Málaga a fines del siglo XV. Introducción a su estudio", Cuadernos de estudios medievales y Ciencias y Técnicas historiográficas, 2-3 (1974-1975), pp. 367-408.

LóPEZ DE CoCA, José Enrique, La tierra de Málaga a fines del siglo XV, Universidad de Granada, Granada, 1977.

LóPez de Coca, José Enrique, "El repartimiento de Vélez Málaga", Anexos de Hispania, 7 (1977), pp. 357-439.

LóPez DE CocA, José Enrique, "Privilegios fiscales y repoblación en el reino de Granada (1485-1520)", Baetica, 2 (1979), pp. 205-223.

López de Coca, José Enrique y GaLÁn SÁnchez, Ángel (coords.), Actas del VI Coloquio Internacional de Historia Medieval de Andalucía: las ciudades andaluzas, siglos XIIIXVI, Estepona, 1990, Universidad de Málaga, Málaga, 1991.

LÓPEZ DE CocA, José Enrique, "La repoblación de Torrox", Pedro J. Arroyal Espigares (coord.), El repartimiento de Torrox, Universidad de Granada, Granada, 2006, pp. 9-60.

LóPEz DE CocA, José Enrique, "Fuengirola, un caso de repoblación fallida", Jábega, 100 (2009), pp. 55-60. 
López DE CocA, José Enrique, "Los últimos repartimientos medievales: el Reino de Granada", Antonio Malpica Cuello, Rafael Gerardo Peinado Santaella y Adela Fábregas García (coords.), Historia de Andalucía: VII Coloquio “¿Qué es Andalucía? Una revisión histórica desde el Medievalismo”, Universidad de Granada, Granada, 2010, pp. 309-342. López Estudillo, Antonio, "Paisaje y poblamiento en la Campiña de Córdoba", Ramón Garrabou Segura y José Manuel Naredo (eds.), El paisaje en perspectiva histórica. Formación y transformación del paisaje en el mundo mediterráneo, Institución Fernando el Católico, Universidad de Zaragoza, Zaragoza, 2008, pp. 259-277.

LÓPEZ RIDER, Javier, "Los molinos del río Monturque en el término municipal de Santaella (Córdoba): molino de don Martín, un legado histórico y tecnológico", Actas del $8^{\circ}$ Congreso Internacional de Molinología, Diputación de Pontevedra, Tui (Vigo), 2012, pp. 145-156.

LÓPEZ Rider, Javier, Estudio sobre construcciones hidráulicas e industriales de Santaella (Córdoba), Diputación Provincial de Córdoba, Córdoba, 2013.

López Rider, Javier, "Aportación al estudio de la hacienda del concejo de Córdoba a fines de la Edad Media”, Historia. Instituciones. Documentos, 41 (2014), pp. 275-319. LÓPEZ RidER, Javier, "La producción de carbón en el reino de Córdoba a fines de la Edad Media: un ejemplo de aprovechamiento del monte mediterráneo", Anuario de Estudios Medievales, 46/2 (2016), pp. 819-858.

LóPEz Rider, Javier, Varela Romero, Juan y Díaz Hidalgo, Rafael Javier, "Los molinos de cubo de Montoro (Córdoba)", Actas del $9^{\circ}$ Congreso Internacional de Molinología. Ingenios tradiciones: recursos de futuro, Diego Marín S. L., Murcia, 2017, pp. 445-457. LóPez Rider, Javier, Santaella y el suroeste de la Campiña cordobesa en la Baja Edad Media, 2 tomos, UCOPress, Universidad de Córdoba, tesis defendida el 30 de junio de 2017 (identificador: http://helvia.uco.es/xmlui/handle/10396/14903).

LÓPEz Rider, Javier, “Organización y configuración territorial del reino de Córdoba en tiempos de Alfonso X (1252-1284)”, Norba. Revista de Historia, (en prensa).

LÓPEz RidER, Javier, "The vegetal landscape of the southwest of Cordoba: a simple of the natural environment of Andalusia in the Late Middle Ages, Journal of Medieval Iberian Studies, vol. 10/3 (2018), pp. 364-384.

LóPez Rider, Javier, "Paisajes hídricos y poblamiento en la Campiña cordobesa a fines de la Edad Media", Riparia, 4 (2018), pp. 111-145.

Mackay, Angus, La España de la Edad Media. Desde la frontera hasta el Imperio, 1000-1500, Madrid, 1995 (5 Ed.).

Malpica Cuello, Antonio, El concejo de Loja (1486-1508), Universidad de Granada, Granada, 1981.

Malpica Cuello, Antonio, "La villa de Motril y la repoblación de la costa de Granada (1489-1510)", Cuadernos de estudios medievales y ciencias y técnicas historiográficas, 10-11 (1983), pp. 169-206. 
Malpica Cuello, Antonio, "Modificaciones en la estructura de poblamiento de la costa granadina a raíz de la conquista castellana", Arqueología espacial (ejemplar dedicado a Época romana y medieval), 5 (1984), pp. 201-220.

Malpica Cuello, Antonio, "La formación de un territorio fronterizo medieval: la costa granadina de la época musulmana a la conquista castellana", Arqueología espacial (ejemplar dedicado a Fronteras), 13 (1989), pp. 241-256.

Malpica Cuello, Antonio, "Estructura del poblamiento de la costa de Granada a fines de la Edad Media”, Studia historica. Historia medieval, 7 (1989), pp. 157-186.

Malpica Cuello, Antonio, "Arqueología de los paisajes medievales granadinos: medio físico y territorio en la costa de Granada”, Arqueología y territorio medieval, 2 (1995), pp. 25-62.

Malpica Cuello, Antonio, Poblamiento y castillos en Granada, Fundación El Legado Andalusí, Granada, 1996.

Malpica Cuello, Antonio, Medio físico y poblamiento en el delta del Guadalfeo. Salobreña y su territorio en época medieval, Universidad de Granada, Granada, 1996.

Malpica Cuello, Antonio, "El paisaje vivido y visto. Asentamientos y territorio en el reino de Granada al final de la Edad Media”, Arqueología medieval, 4 (1996), pp. 37-58.

Malpica Cuello, Antonio, "El poblamiento y la organización del espacio”, Manuel Barrios Aguilera y Rafael Gerardo Peinado Santaella (coord.), Historia del reino de Granada, vol. 1, Universidad de Granada y Fundación El Legado Andalusí, Granada, 2000, pp. 249-289. Malpica Cuello, Antonio, "El medio natural y el poblamiento medieval del reino de Granada”, Julián Clemente Ramos (ed.), El medio natural en la España Medieval. Actas del I Congreso sobre ecohistoria e Historia Medieval, Universidad de Extremadura, Cáceres, 2001, pp. 141-162.

Malpica Cuello, Antonio, Los castillos en al-Ándalus y la organización del territorio, Universidad de Extremadura, Cáceres, 2003.

Malpica Cuello, Antonio, "El territorio de Loja a finales de la Edad Media. Reflexiones sobre las transformaciones castellanas en el Reino de Granada", Arqueología y territorio medieval, 10-2 (2003), pp. 233-254.

Malpica Cuello, Antonio, "Un asentamiento fortificado en la frontera nazarí-castellana: Castril de la Peña", Studia historica. Historia medieval (ejemplar dedicado a Fronteras y limites interiores), 24 (2006), pp. 197-225.

Malpica Cuello, Antonio, "Una propuesta de análisis de la arqueología del paisaje. Reflexiones teóricas y un caso concreto de aplicación", Tudmir: Revista del Museo de Santa Clara, 1 (2009), pp. 9-28.

Malpica Cuello, Antonio, Análisis de los paisajes históricos. De al-Ándalus a la sociedad feudal, Alhulia, Granada, 2009.

Malpica Cuello, Antonio, "Castillos, alquerías y ciudades en al-Ándalus. Un debate partiendo del análisis arqueológico", Ángel Luis Molina y Jorge Eiroa (eds.), El castillo medieval en tiempos de Alfonso X El Sabio, Universidad de Murcia, Murcia, 2009, pp. 99-120. 
Malpica Cuello, Antonio y García-Contreras Ruiz, Guillermo, "Asentamientos y explotación de la sal en el valle del Salado y la zona de Sigüenza en época medieval", En la España medieval, 33 (2010), pp. 295-324.

Malpica Cuello, Antonio, Peinado Santaella, Rafael Gerardo y Fábregas García, Adela, Historia de Andalucía: VII Coloquio "¿Qué es Andalucía?. Una revisión histórica desde el Medievalismo", 2009, Universidad de Granada, 2010.

Malpica Cuello, Antonio, "Poblamiento, agricultura y ganadería en el reino nazarí de Granada", Antonello Mattone y Pinuccia F. Simbula (eds.), La Pastorizia Mediterranea: Storia e Diritto (secoli XI-XX), Roma, Università di Sassari, 2011, pp. 41-54.

Malpica Cuello, Antonio, Las últimas tierras de al-Ándalus: paisaje y poblamiento del reino nazarí de Granada, Consorcio para la Conmemoración del Primer Milenio de la Fundación del Reino de Granada, Granada, 2014.

Malpica Cuello, Antonio, "Fortificación en el mundo nazarí (siglos XIII-XV)", Desperta Ferro: Antigua y Medieval (ejemplar dedicado a La Guerra de Granada), 34 (2016), pp. 30-37.

Malpica Cuello, Antonio (ed.), Zonas húmedas en Andalucia Medieval: inicio de un debate, Alhulia, Granada, 2017.

Martín Civantos, José María, Medio Ambiente y arqueología medieval, Alhulia, Granada, 2008.

Martín Civantos, José María y Arod, Hani, "Poblamiento medieval en la cuenca alta del río Nacimiento (Almería)", Boletín del Centro de Estudios Pedro Suárez: Estudios sobre las comarcas de Guadix, Baza y Huéscar, 26 (2013), pp. 35-61.

Martín GutiérRez, Emilio, “Aproximación al repartimiento rural en Jerez de la Frontera: la aldea de Grañina”, En la España medieval, 22 (1999), pp. 355-368.

Martín GutiÉrRez, Emilio, "Los espacios cultivados y los incultos. Aproximación al paisaje rural jerezano en la Baja Edad Media", Francisco Javier Pérez-Embid Wamba (coord.), La Andalucía medieval: Actas de las I Jornadas de Historia Rural y Medio Ambiente (Almonte, mayo de 2000), Universidad de Huelva, Huelva, 2002, pp. 355-376.

Martín Gutiérrez, Emilio, La identidad rural de Jerez de la Frontera. Territorio y poblamiento durante la Baja Edad Media, Universidad de Cádiz, Cádiz, 2003.

Martín Gutiérrez, Emilio, "Análisis de la toponimia y aplicación al estudio del poblamiento. El Alfoz de Jerez de la Frontera durante la Baja Edad Media", Historia. Instituciones. Documentos, 30 (2003), pp. 257-300.

Martín Gutiérrez, Emilio, “Territorio. Paisaje. Poblamiento. La organización del alfoz jerezano durante los siglos bajomedievales”, Revista de historia de Jerez, 10 (2004), pp. 33-56.

Martín GutiérRez, Emilio, La organización del paisaje rural durante la Baja Edad Media: el ejemplo de Jerez de la Frontera, Universidad de Sevilla y Universidad de Cádiz, 2004. 
Martín GutiÉrRez, Emilio, "El paisaje rural como objeto de estudio. Siglos XIII al XVI. Tema de investigación y perspectivas. Valor patrimonial", Medievalismo, 17 (2007), pp. 121-150.

Martín GutiÉRrez, Emilio (coord.), El paisaje rural en Andalucía Occidental durante los siglos bajomedievales: actas de las I Jornadas Internacionales sobre paisajes rurales en época medieval, Cádiz, abril de 2009, Universidad de Cádiz, Cádiz, 2011.

Martín GutiérRez, Emilio, "Reflexiones en torno a los paisajes rurales en Jerez de la Frontera durante el último cuarto del siglo XIII", Manuel Antonio Barea Rodríguez et alii (coords.), Aniversario de la incorporación de jerez a la Corona de Castilla 12642014, Ayto. de Jerez, 2014, pp. 175-193.

Martín Gutiérrez, Emilio, "Interacción, sociedad y medio ambiente. El entorno de la laguna de Los Tollos (Andalucía Occidental), siglos XIII al XV", Studia historia. Historia medieval (ejemplar dedicado a Tierra y sociedad campesina), 32 (2014), pp. 103-130. Martín GutiérRez, Emilio, Paisajes, ganadería y medio ambiente en las comarcas gaditanas: siglos XIII al XVI, Universidad de Cádiz, Cádiz, 2015.

Martín GutiÉrRez, Emilio, "El aprovechamiento de humedales y marismas en el término de Cádiz: segunda mitad del siglo XIII", Lázaro Gabriel Lagóstena Barrios (ed.), Qui lacus aquae stagna paludes sunt...: estudios históricos sobre humedales en la Bética, Seminario de Agustín de Horozco de Estudios Económicos de Historia Antigua y Medieval, ed. Tréveris, Cádiz, 2015, pp. 121-147.

Martín Gutiérrez, Emilio, "Paisajes imaginados y paisajes reales a finales de la Edad Media. Humedales y marismas en las comarcas gaditanas", María Isabel DEL VAL VALDIVIESO (ed.), El agua en el imaginario medieval: los reinos ibéricos en la Baja Edad Media, Universidad de Alicante, Alicante, 2016, pp. 17-40.

Martín GutiÉrRez, Emilio, "Paisajes palustres entre la desembocadura del Guadalquivir y el Guadalete durante los siglos XIII al XV", Antonio Malpica Cuello (ed.), Zonas húmedas en Andalucia Medieval: inicio de un debate, Alhulia, Granada, 2017, pp. 15-49. Martín Palma, $\mathrm{M}^{\mathrm{a}}$ Teresa, Los repartimientos de Vélez-Málaga: primer repartimiento, Universidad de Granada, Granada, 2005.

Martínez Castro, Antonio y Tristell MuÑoz, Francisco Javier, "Localizados los restos de la Torre de Albaén, importante bastión almohade del noroeste de la campiña cordobesa (término municipal de Córdoba)", Qurtuba. Estudios andalusies, 3 (1998), pp. 256-258. Martínez CASTRO, Antonio, "Breves notas sobre la funcionalidad de las torres islámicas de la campiña de Córdoba", Antiquitas, 15 (2003), pp. 79-83.

Martínez Castro, Antonio, "Una hipótesis sobre la ubicación de la torre islámica de Diezma Ayusa (campiña de Córdoba)", Antiquitas, 15 (2003), pp. 65-71.

Martínez Castro, Antonio, "El asentamiento medieval de Almazán. Estudio sobre su ubicación”, Almazán, 8 (2004), pp. 11-19. 
Martínez Castro, Antonio, "Fortificaciones y poblamientos islámicos del entorno de La Rambla", Actas de las II Jornadas de Patrimonio Cultural (La Rambla, febrero de 2007), Ayto. de La Rambla, 2008, pp. 33-82.

Martínez Castro, Antonio, "La Torre de Don Lucas (La Victoria, Córdoba), una torre de alquería en el sur de al-Ándalus”, Antiquitas, 27 (2015), pp. 137-171.

Mayoral Herrera, Victorino y Celestino Pérez, Sebastián (eds.), Actas del V Simposio Internacional de Arquitectura de Mérida: Tecnologías de información geográfica y análisis arqueológico del territorio, CSIC, Madrid, 2011.

Millson, Dana C. E., Experimentation and Interpretation: the Use of Experimental Archaeology in the Study of the Past, Oxbow Books, Oxford, 2010.

Montes Romero-CAmacho, Isabel, Propiedad y explotación de la tierra en la Sevilla de la Baja Edad Media, Fundación Fondo de Cultura de Sevilla, Sevilla, 1988.

Montes Romero-CAmacho, Isabel, El paisaje rural sevillano en la Baja Edad Media, Diputación Provincial de Sevilla, Sevilla, 1989.

Mотоs Guirao, Encarnación, “El Castellón de Vélez Rubio y el poblamiento medieval de los Vélez”, Revista velezana, 19 (2000), pp. 5-14.

Nieto Cumplido, Manuel, "El "Libro de diezmos de donadíos" de la catedral de Córdoba", Cuadernos de Estudios Medievales y Ciencias y Técnicas Historiográficas, 4-5 (1979), pp. 125-162.

Nieto Cumplido, Manuel, Villa del Río en la Baja Edad Media, Imprenta San Pablo, Córdoba, 1979.

Nieto Cumplido, Manuel, Corpus Mediaevale Cordubense, 2 vols., Montes de Piedad y Caja de Ahorros, Córdoba, 1979-1980.

Nieto Cumplido, Manuel, "Castro del Río en la Baja Edad Media (1236-1400)", Castro del Río. Bosquejo histórico de una villa andaluza, Ayto. de Castro del Río (Córdoba), 1986. Nieto Cumplido, Manuel, "Santaella en la Edad Media", Santaella. Estudios históricos de una villa cordobesa, Círculo de labradores, Santaella (Córdoba), 1986, pp. 41-83.

Nieto Cumplido, Manuel, La historia de la Iglesia en Córdoba. Reconquista y restauración (1146-1326), Monte de Piedad y Caja de Ahorros, Córdoba, vol. II, 1991.

O’Callaghan, Joseph F., Reconquest and crusade in medieval Spain, University of Pennsylvania Press, 2004.

Pareja Serrano, Ma del Carmen, El repartimiento de Baza y la repoblación. Siglo XV, memoria de licenciatura inédita, Granada, 2 vols., 1981.

Peinado Santaella, Rafael Gerardo, "La repoblación de la Tierra de Granada: la fundación de Guadahortuna (1503-1505)”, José Enrique López de Coca Castañer (ed.), Estudios sobre Málaga y el Reino de Granada en el V Centenario de la Conquista, Diputación Provincial de Málaga, Málaga, 1987, pp. 363-381.

Peinado Santaella, Rafael Gerardo, La repoblación de la tierra de Granada. Los Montes orientales (1485-1525), Universidad de Granada, Granada, 1989. 
Peinado Santaella, Rafael Gerardo y Osorio Pérez, Ma José, “El Libro de repartimiento de Montejícar (1527). Comentario y edición”, Revista del Centro de Estudios Históricos de Granada y su Reino, 2a época, 4 (1990), pp. 71-112.

Peinado Santaella, Rafael Gerardo, "La repoblación del Reino de Granada. Estado de la cuestión y perspectivas de la investigación", La Reconquista y Repoblación de los Reinos Hispánicos. Estado de la cuestión de los últimos cuarenta años, Actas del Coloquio de la V Asamblea General de la Sociedad Española de Estudios Medievales, Diputación General de Aragón, Zaragoza, 1991, pp. 273-334.

Peinado Santaella, Rafael Gerardo, "Repoblación, organización y distribución del espacio en los Montes de Granada (finales del siglo XV-mediados del siglo XVI)", Miguel Ángel Ladero Quesada (ed.), La incorporación de Granada a la Corona de Castilla, Actas del Symposium conmemorativo del Quinto Centenario, Diputación Provincial de Granada, Granada, 1993, pp. 559-575.

Peinado Santaella, Rafael Gerardo, "Una aportación documental sobre el poblamiento, el paisaje agrario y la propiedad de la tierra de dos alquerías de la Vega de Granada: Chauchina y El Jau a finales del período nazarí", Revista del Centro de Estudios Históricos de Granada y su Reino, 2a época, 10 (1996-1997), pp. 19-92.

Peinado Santaella, Rafael Gerardo, "El Reino de Granada después de la conquista: La sociedad repobladora según los libros de repartimiento", Manuel González Jiménez (ed.), La Península Ibérica en la Era de los Descubrimientos (1391-1492), Actas de las III Jornadas Hispano-Portuguesas de Historia Medieval II, Consejería de Cultura de la Junta de Andalucía y Universidad de Sevilla, Sevilla, 1997, pp. 1575-1630.

Peinado Santaella, Rafael Gerardo, "La sociedad repobladora: el control y la distribución del espacio", Rafael Gerardo Peinado Santaella (ed.), Historia del reino de Granada I. De los orígenes a la época mudéjar (hasta 1502), Universidad de Granada y El Legado Andalusí, Granada, 2000, pp. 477-524.

Peinado Santaella, Rafael Gerardo y Osorio Pérez, Ma José, "Del repartimiento al despojo: Colomera, un episodio de la repoblación del reino de Granada", Homenaje a $M^{a}$ Angustias Moreno Olmedo, Universidad de Granada, Granada, 2006, pp. 683-726.

PÉrez-EmBid WAMBA, Francisco Javier, "Un despoblado bajomedieval en el Aljarafe: Villanueva Nogachet”, Archivo hispalense, tomo 61, 188 (1978), pp. 145-149.

PÉREZ-EMBID WAMBA, Francisco Javier, Aracena y su sierra: la formación histórica de una comunidad andaluza (siglos XIII-XVIII), Diputación Provincial de Huelva, Huelva, 1995. PÉrez-Embid Wamba, Francisco Javier (coord.), La Andalucía medieval: Actas de las I Jornadas de Historia Rural y Medio Ambiente (Almonte, mayo de 2000), Universidad de Huelva, Huelva, 2002.

PÉRez-Embid WAmbA, Francisco Javier, "En el entorno rural de la Córdoba cristiana: el pago de El Tablero de la Arruzafa (siglos XIII-XIX)", en Ricardo Córdoba de la Llave et alii (coords.), Estudios en homenaje al profesor Emilio Cabrera, Universidad de Córdoba, Córdoba, 2015, pp. 413-430. 
Quesada Quesada, Tomás, "El poblamiento medieval en las sierras subbéticas de Jaén y Granada: el caso de Sierra Mágina”, Studia historica. Historia medieval, 9 (1991), pp. 159-182.

Quesada Quesada, Tomás y Jiménez SÁnchez, Milagros, "En los confines de la conquista castellana: toponimia y poblamiento en los montes granadino-giennenses en el siglo XIII según la documentación cristiana", Revista del centro de Estudios Históricos de Granada y su Reino, 6 (1992), pp. 51-80.

Quesada Quesada, Tomás y Motos Guirao, Encarnación, "Las modificaciones en el hábitat en el sur de la provincia de Jaén, tras las conquistas castellanas del siglo XIII", III Congreso de Arqueología Medieval Española, 1989, Oviedo, vol. 2, Madrid, 1992, pp. 377-382.

Quesada Quesada, Tomás, El paisaje rural de la Campiña de Jaén en la Baja Edad Media según los libros de dehesas, Universidad de Jaén, Jaén, 1994.

Quesada Quesada, Tomás, "Formas de poblamiento en un área rural de al-Ándalus: el valle del río Jumilla", Arqueología y territorio medieval, 2 (1995), pp. 5-24.

Quesada Quesada, Tomás, "Poblamiento y fortificación del territorio en los siglos XIIXIII. El caso de las sierras meridionales de Jaén", Antonio Malpica Cuello (coord.), Castillos y Territorio en al-Ándalus, Athos Pérgamos, Granada, 1998, pp. 141-163.

Ríos Saloma, Martín Federico, "La Reconquista: génesis de un mito historiográfico", Historia y grafia, 30 (2008), pp. 191-216.

Ríos Saloma, Martín Federico, "La "Reconquista": una aspiración peninsular? Estudio comparativo entre dos tradiciones historiográficas", Bulletin du Centre d'études médiévales d'Auxerre, hors-série, 2 (2008), pp. 1-15.

Ríos Saloma, Martín Federico, La Reconquista, una construcción historiográfica (siglos XVI-XIX), Marcial Pons, Madrid, 2011.

Rodríguez Molina, José, El Reino de Jaén en la Baja Edad Media. Aspectos demográficos y económicos, Universidad de Granada, Granada, 1978.

Rodríguez Molina, José, "Andalucía II. El reino de Granada. Líneas de investigación actuales", Cristina Segura Graíño (ed.), Presente y futuro de la Historia Medieval en España: Actas de las I Jornadas sobre la investigación medieval en las comunidades autónomas, Universidad Complutense de Madrid, Madrid, 1990, pp. 237-270.

Ros, Jérôme, Puig, Carole y Ruas, Marie-Pierre, "Les denrées végétales dans le nord de la Catalogne d'après les sources historiques et archéobotaniques $\left(\mathrm{X}^{\mathrm{e}}-\mathrm{XV}^{\mathrm{e}}\right.$ siècles): productions et échanges", Archéologie du midi médiéval, tome 32 (2014), pp. 123-138. Rufo Ysern, Paulina, "Problemas de términos entre Carmona y Écija a fines de la Edad Media", Archivo hispalense (ejemplar dedicado al I Congreso de Historia de Carmona), tomo 80, 243-245 (1997), pp. 363-386.

Rufo Ysern, Paulina, "Usurpaciones de tierras y derechos comunales en Écija durante el Reinado de los Reyes Católicos: la actuación de los jueces de términos", Historia. Instituciones. Documentos, (24) 1997, pp. 449-496. 
Rufo Ysern, Paulina, "Los jueces de términos en Écija: procedimiento de revisión de las usurpaciones en el siglo XV", Antonio Muñoz Buendía y Julián Pablo Díaz López (coords.), Herbajes, trashumantes y estantes: la ganadería en la Península Ibérica (épocas medieval y moderna), Instituto de Estudios Almerienses, Almería, 2002, pp. 131-148.

Ruiz Povedano, José Ma "'Poblamiento y frontera. La política repobladora de Alfonso XI en la villa de Alcaudete", Boletín del Instituto de Estudios Giennenses, 101 (1980), pp. 1-14. Ruiz Povedano, José Ma " "Transformación del paisaje urbano y territorial del Álora al final de la Edad Media", Jábega, 88 (2001), pp. 3-19.

Ruiz Povedano, José Ma "El "juzgado de términos, veredas y cañadas" de la ciudad y obispado de Córdoba (1477-1478)", Meridies: revista de historia medieval, 10 (2012), pp. 109-150.

Salvatierra Cuenca, Vicente, “Jaén en los siglos XIII y XIV. La formación de la ciudad cristiana”, Revista del Centro de Estudios Históricos de Granada y su Reino, 7 (1993), pp. 149-168.

Salvatierra Cuenca, Vicente, "Jaén, tierra bien encastillada. La fortificación medieval, capacidad de defensa y uso agrícola”, Andalucía en la historia, 26 (2009), pp. 94-97. Sánchez Villaespesa, Francisco, "Las torres de la Campiña de Córdoba en el siglo XIII. Un sistema de defensa de las comunidades rurales en época almohade", Qurțba. Estudios andalusíes, 1 (1996), pp. 157-170.

Sanz Fuentes, Josefa Ma "'Repartimiento de Écija", Historia. Instituciones. Documentos, 3 (1976), pp. 534-551.

Sanz SAncho, Iluminado, La Iglesia y el obispado de Córdoba en la Baja Edad Media (1236-1426), Universidad Complutense de Madrid, Madrid, 2 vols., 1989.

SAnz SANCho, Iluminado y DEL Pino García, José Luis, "Parroquias y núcleos rurales de población en el obispado de Córdoba en la Baja Edad media", Historia Medieval: actas del II Congreso de Historia de Andalucía, vol. 2, Córdoba, 1994, pp. 5-17.

SAnz SAncho, Iluminado, Geografía del Obispado de Córdoba en la baja edad media, Polifemo, Madrid, 1995.

Segura Graíño, Cristina, El libro del Repartimiento de Almería, Universidad Complutense de Madrid, Madrid, 1982.

Segura Graíño, Cristina, "Los repartimientos medievales andaluces. Estado de la cuestión”, Anuario de Estudios Medievales, 12 (1982), pp. 625-640.

Segura Graíño, Cristina, La formación del pueblo andaluz: los repartimientos medievales, Istmo, Madrid, 1983.

Segura Graíño, Cristina, "Poblaciones recientes sobre la historia de Andalucía en la Edad Media”, Hispania, vol. 46, 163 (1986), pp. 421-427.

Segura GraíNo, Cristina (coord.), Actas del IV Coloquio de Historia Medieval Andaluza: Relaciones exteriores del Reino de Granada, Instituto de Estudios Almerienses, Almería, 1988. 
Segura Graíño, Cristina, "Presencia Portuguesa en la conquista y repoblación de Almería (s. XV)", Actas das II Jornadas Luso-Espanholas de História Medieval, Porto, 1989, III, pp. 841-849.

SANChO DE Sopranis, Hipólito, "La repoblación y el repartimiento de Cádiz por Alfonso X”, Hispania, XV (1955), pp. 483-539.

TAlbert, Richard J. A. y Unger, Richard W., Cartography in antiquity and the Middle Ages: fresh perspectives, new methods, Brill, Leiden, 2008.

Toro Ceballos, Francisco y Rodríguez Molina, José (coords.), VI Estudios de Frontera: población y poblamiento: homenaje a don Manuel González Jiménez, Alcalá la Real, noviembre de 2005, Diputación provincial de Jaén, Jaén, 2006.

Torres Delgado, Cristóbal, "La ciudad de Baza y el Libro de Repartimiento después de su conquista (4-Diciembre-1489)", Acta histórica et archaeologica medieaevalia, 22 (2001), vol.2, pp. 747-794.

Trillo SAN José, $\mathrm{M}^{\mathrm{a}}$ del Carmen, "El poblamiento de la Alpujarra a la llegada de los cristianos", Studia historica. Historia medieval, 7 (1989), pp. 187-208.

Trillo SAn José, Mª del Carmen, La Alpujarra al final de la Edad Media, Universidad de Granada, Granada, 1991.

Trillo SAn José, Ma del Carmen, "Poblamiento medieval en la Alta Alpujarra granadina", Juan Manuel Campos Carrasco y Francisco Nocete Calvo (coords.), Investigaciones arqueológicas en Andalucía, 1985-1992. Proyectos, Huelva del 25 al 29 de enero de 1993, Junta de Andalucía, Sevilla, 1993, pp. 725-730.

Trillo San José, Ma del Carmen, La Alpujara antes y después de la conquista castellana, Universidad de Granada, Granada, 1998.

Trillo SAn José, $M^{\text {a }}$ del Carmen, "La alquería y su territorio en al-Ándalus: estrategias sociales de organización y conservación", Arqueología espacial (ejemplar dedicado a Arqueología espacial y espacios agrarios), 26 (2006), pp. 243-262.

Trillo San José, Ma del Carmen, "La organización del espacio de la alquería en la frontera nororiental del reino de Granada", Studia historica. Historia medieval (ejemplar dedicado a Fronteras y límites interiores), 24 (2006), pp. 227-240.

Trillo SAN José, $M^{a}$ del Carmen, "Comunidades rurales en el Reino Nazarí", Antonio Malpica Cuello, Rafael Gerardo Peinado Santaella y Adela Fábregas García, Historia de Andalucia: VII Coloquio "¿Qué es Andalucía? Una revisión histórica desde el Medievalismo", Universidad de Granada, Granada, 2010, pp. 103-118.

Valor Piechotta, Magdalena, "Las fortificaciones de la Baja Edad Media en la provincia de Sevilla", Historia. Instituciones. Documentos, 31 (2004), pp. 687-700.

Valor Piechotta, Magdalena, (coord.), Historia y arqueología de la Constancia medieval, Universidad de Sevilla, Sevilla, 2011. 